\title{
Imaging Review of Hockey-related Lower Extremity Injuries
}

\author{
R. Davis Holmes, MD, MASc, FRCPC ${ }^{10}$ Yet Yen Yan, MBBS, FRCR, MMED ${ }^{1,2(0)}$ \\ Paul I. Mallinson, MBChB, FRCR, FRCPC ${ }^{10}$ Gordon T. Andrews, MD, FRCPC ${ }^{1}$ \\ Peter L. Munk, MDCM, FRCPC, FSIR, FFRRCSI (Hon) ${ }^{1}$ Hugue A. Ouellette, BSc, MD, FRCPC ${ }^{10}$
}

${ }^{1}$ Musculoskeletal Section, Department of Radiology, Vancouver

Address for correspondence R. Davis Holmes, MD, MASc, Gordon and General Hospital, Vancouver, BC, Canada

2 Department of Radiology, Changi General Hospital, Singapore Leslie Diamond Health Care Centre, 2775 Laurel Street, 11th Floor, Vancouver, BC, Canada V5Z1M9 (e-mail: davisholmes@gmail.com).

Semin Musculoskelet Radiol 2022;26:13-27.

\author{
Abstract \\ Keywords \\ - sports imaging \\ - hockey \\ - magnetic resonance \\ imaging \\ - lower extremity \\ injuries
}

Hockey is a fast-paced contact sport with a high incidence of injuries. Although injuries are more frequent among elite players, recreational hockey injuries are a common issue faced by primary care and emergency physicians. Lower extremity injuries in hockey are particularly important because they account for approximately a third of all injuries and $>60 \%$ of all overuse injuries. This pictorial review provides the general and specialty trained radiologist with a knowledge of the patterns of lower extremity injury that occur in ice hockey.
This article focuses on hockey-related lower extremity injuries, which account for approximately a third of all sustained injuries, ${ }^{1,2}$ and result in significant playing time loss with considerable economic hockey-related consequences for professionals. ${ }^{3}$ Similar to other sports, specific patterns of injury can result from trauma or overuse. A knowledge of these injury patterns, as well as common asymptomatic abnormal imaging findings is paramount for radiologists to be able to interpret lower extremity imaging accurately in hockey players.

\section{Hip/Groin}

\section{General}

Hip/groin injuries are common in hockey and increasing in incidence among younger players as well as those playing at higher levels. ${ }^{4,5}$ Among National Hockey League players, the incidence of hip/groin injuries is $\sim 20$ per 100 players per year. ${ }^{6}$ For comparison, ice hockey has the second highest rate of hip/groin injuries after men's soccer and an incidence that is 1.7 times that of men's american football. ${ }^{7}$ Hip/groin issues affect all positions similarly. ${ }^{8,9}$

Strains of various structures of the hip/groin account for $50 \%$ of injuries, most of which occur via noncontact mech- anisms. The hip/groin is the most common site of overuse injuries, accounting for up to $48 \%$ of cases and recurrence rates up to $63 \% .^{10}$ Contusions account for $28 \%$ of hip/groin injuries; fractures $(5 \%)$, dislocations $(<1 \%)$, and lacerations $(5 \%)$ are relatively uncommon. ${ }^{4}$

The differential diagnosis for hip/groin pain in a skating athlete is broad and can be divided into musculoskeletal (intraor extra-articular), visceral, neurologic, and referred (-Table 1). ${ }^{11,12}$ Although all imaging modalities have a role in the evaluation of hip/groin pain, magnetic resonance imaging (MRI) represents the single best imaging test in hockey players because it is sensitive to pathologies of bone, joints and, the complex soft tissues around the hip and pubic symphysis. ${ }^{13}$

\section{Extra-articular}

An ice hockey player is connected to a near-frictionless surface by nothing more than thin skate blades. As a result, core muscle engagement is vital to skating maneuvers while simultaneously performing upper body actions such as shooting, stick handling, passing, and checking. A knowledge of skating technique aids in understanding why core muscle groin injuries occur so commonly in hockey and occur via a noncontact mechanism in most cases $(60 \%) .{ }^{14}$
Issue Theme Winter Sports; Guest Editors, Hugue A. Ouellette, BSc, MD, FRCPC and Peter L. Munk, MDCM, FRCPC, FSIR, FFRRCSI(Hon) (c) 2022. Thieme. All rights reserved. Thieme Medical Publishers, Inc., 333 Seventh Avenue, 18th Floor, New York, NY 10001, USA
DOI https://doi.org/ 10.1055/s-0041-1731795. ISSN 1089-7860. 
Table 1 Differential diagnosis of hip/groin pain in ice hockey players

\begin{tabular}{|c|c|}
\hline Musculoskeletal & Visceral \\
\hline $\begin{array}{l}\text { Intra-articular } \\
\text { Hip joint } \\
\text { Labral tear } \\
\text { Osteochondral lesion } \\
\text { Femoroacetabular } \\
\text { impingement } \\
\text { Osteoarthritis } \\
\text { Pubic symphysis } \\
\text { Osteitis pubis } \\
\text { Extra-articular } \\
\text { Osseous } \\
\text { Fractures } \\
\text { (stress and nonstress) } \\
\text { Osteomyelitis } \\
\text { Contusion/"hip pointer" } \\
\text { Apophysitis/ } \\
\text { Apophyseal avulsion } \\
\text { Muscle/Tendon } \\
\text { Adductor-rectus injury } \\
\text { Lateral abdominal } \\
\text { aponeurosis injury } \\
\text { Tendinosis } \\
\text { (any compartment) } \\
\text { Nerve } \\
\text { Ilioinguinal/ } \\
\text { Genitofemoral/ } \\
\text { Obturator entrapment } \\
\text { Referred } \\
\text { Knee, sacroiliac joint, or } \\
\text { lumbar pathologies }\end{array}$ & $\begin{array}{l}\text { Genitourinary } \\
\text { Genital trauma } \\
\text { Urinary tract calculi } \\
\text { Urinary tract infection } \\
\text { Bowel } \\
\text { a Inflammatory bowel } \\
\text { disease } \\
\text { Appendicitis }\end{array}$ \\
\hline
\end{tabular}

Focusing on the movement of single-leg forward skating mechanics can be divided into three phases: glide phase, push-off phase, and repositioning phase (-Fig. 1a). ${ }^{15}$ During the glide phase in preparation for the push-off phase, a skater has a flexed hip and knee. During the push-off phase, a skater's leg has significant coronal and sagittal plane movement. The propelling leg undergoes hip abduction, extension, and external rotation as well as knee extension with relatively minor plantar flexion (-Fig. 1b). ${ }^{16}$ Forceful eccentric contraction of the adductors to decelerate the hip results in disproportionately increased adductor activation compared with other muscle groups. ${ }^{17}$ This is a proposed pathomechanism for adductor injury, which is the most commonly strained lower extremity muscle compartment.

The groin pain often referred to as "hockey groin syndrome" is usually exacerbated by hip extension from a seated position, the movement performed during the push-off phase of skating as well as taking a slap shot. Unfortunately, injury to multiple closely related structures near the pubic symphysis can result in this clinical presentation. Thorough review articles offer a detailed discussion of the complex anatomy in this region and a discussion of each type of injury. ${ }^{18,19}$ The following are descriptions of the most common extra-articular injuries based on the literature and our experience.

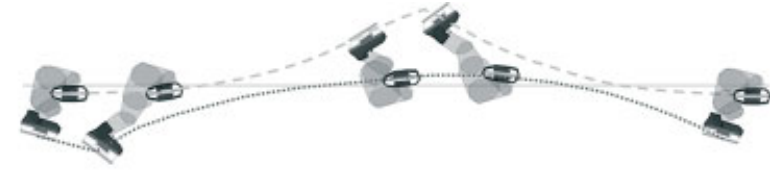

a

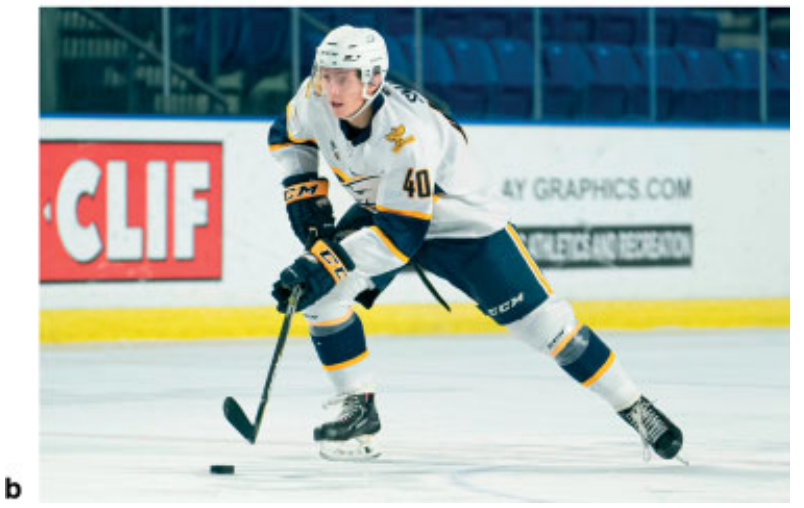

Fig. 1 Phases of the skating stride. (a) Overhead view of a single cycle of the skating stride is demonstrated. Colored bars along the bottom of the diagram indicate the phase of the left leg. Both legs go through all three phases but are not in the same phase simultaneously. The left leg starts in the glide phase (orange) while the right leg generates force during its push-off phase. At the end of the glide phase, the left leg moves laterally to enter its push-off phase (blue). Finally, after pushing off, the left leg enters the repositioning phase (gray) as it adducts back in front of the player. After repositioning, the left leg reenters the glide phase, completing a full cycle. (b) Hockey player with his left leg positioned at the end of the push-off phase with hip abduction-extension and knee extension. The right lower extremity is positioned in the glide phase with significant knee and hip flexion. Used with the player's permission.

\section{Rectus-Adductor Injuries}

Comparing all collegiate sports, the highest rates of hip adductor and flexor strains occur in ice hockey and soccer. ${ }^{14}$ Ice hockey has one of the highest rates of recurrent hip muscle strains (15-30\%). ${ }^{6,14}$ Rectus-adductor injuries most commonly involve the rectus abdominis-adductor longus (RA-AL) aponeurosis, but they also include injuries isolated to the tendon/myotendinous junction of adductors and abdominal muscles. Injuries previously clinically diagnosed as adductor strains often have associated lower abdominal pain and in fact are the result of injury of the RA-AL aponeurosis based on imaging. ${ }^{20}$

MRI findings of injuries involving the RA-AL aponeurosis include focal pubis bone marrow edema (BME), RA-AL aponeurosis attachment tearing with an associated secondary cleft $\operatorname{sign}^{21}$ or superior cleft sign, ${ }^{22}$ as well as findings of secondary osteitis pubis (-Fig. 2). These findings are more commonly found together rather than in isolation. ${ }^{23}$ In a recent study of kicking athletes, the superior cleft sign, which results from tenoperiosteal tearing of the RA-AL aponeurosis from the anterior pubis, was the most commonly observed finding. When the superior cleft sign is an isolated finding, it was associated with the best response to corticosteroids. ${ }^{24}$

Interpretation of hip/groin MRI must be made in conjunction with the clinical examination because up to $77 \%$ of asymptomatic high-level players have objective imaging 

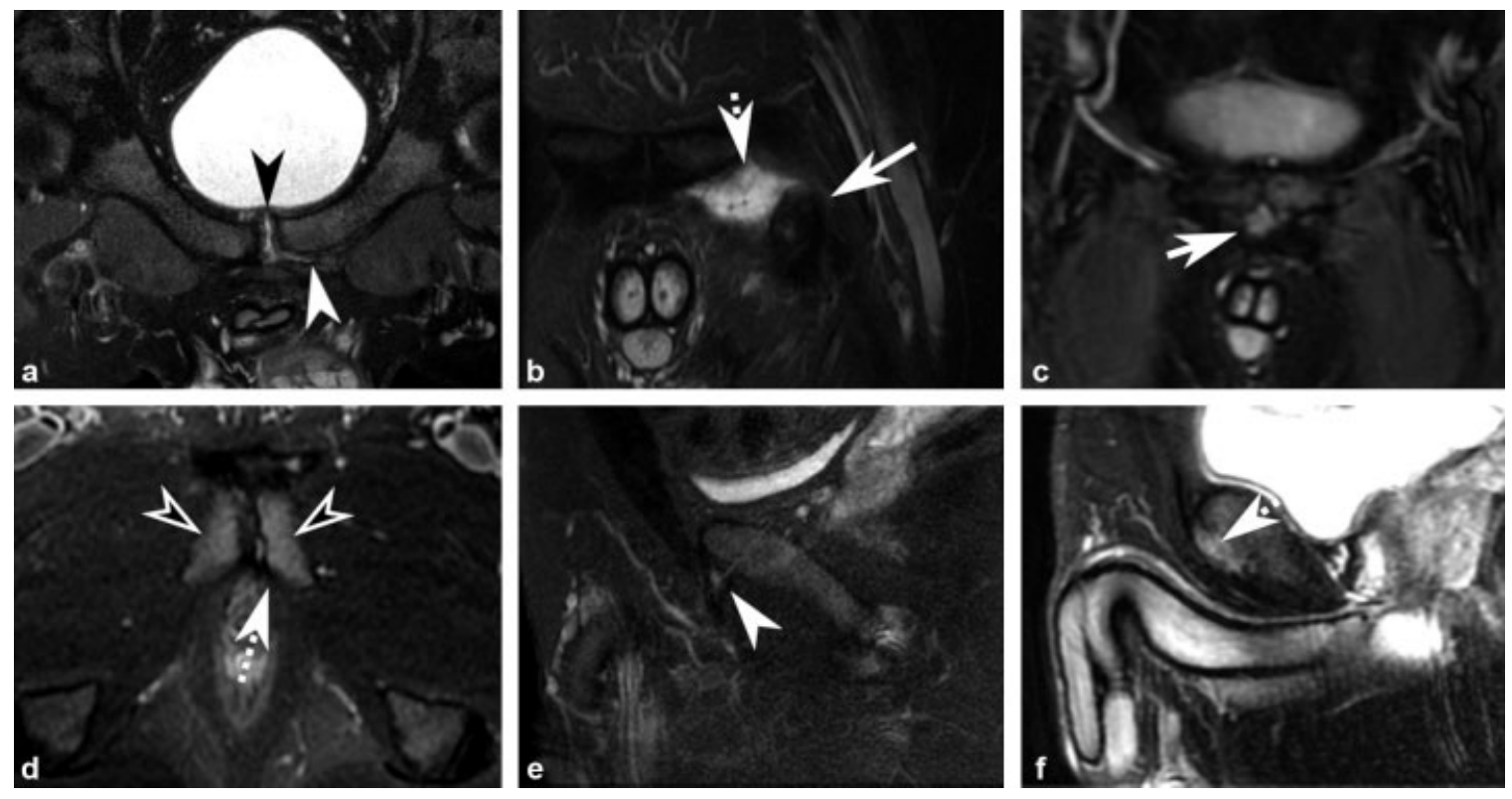

Fig. 2 Examples of rectus abdominis-adductor longus (RA-AL) aponeurosis injuries in hockey players. (a) Axial oblique proton-density fatsuppressed (PDFS) sequence demonstrates a left RA-AL aponeurosis tenoperiosteal tear with linear fluid signal (white arrowhead) communicating with the primary cleft of the pubic symphysis. Pubic symphysis disk protrusion or osteophyte (black arrowhead) is a degenerative finding, likely secondary and asymptomatic. (b) Coronal T2-weighted fat-suppressed (T2FS) sequence of the left groin demonstrates avulsion of the left adductor longus origin (long white arrow) with associated fluid signal at its prior site of attachment (short dashed arrow). (c) Coronal T2FS demonstrates extensive midline tearing between the RA-AL aponeurosis and the underlying anterior pubic symphysis (short white arrow). (d) Axial T2FS at the level of the pubic symphysis demonstrates bilateral symphyseal bone marrow edema (open arrowheads) and a left-sided linear parasymphyseal hypointensity (long dashed arrow) in keeping with a stress fracture at the adductor origins. (e) Sagittal T2FS through the left RAAL aponeurosis shows intrasubstance high signal (white arrowhead) of the adductor longus proximal tendon origin in keeping with tendinosis. (f) Sagittal T2FS through the left pubis demonstrates complete focal tearing (short dashed arrow) of the RA-AL aponeurosis tenoperiosteal attachment.

abnormalities. $^{25}$ This issue is not unique to hockey injury imaging. ${ }^{26} \mathrm{BME}$ and the secondary cleft sign are present in 20 to $25 \%$ of asymptomatic players, and $36 \%$ of patients have asymptomatic RA-AL aponeurosis abnormalities. ${ }^{25}$ In a study of chronic groin pain that included ice hockey players, only adductor tendinopathy was more highly associated with symptomatic players. ${ }^{23}$ Asymptomatic MRI findings have not been found to portend future injuries on follow-up studies. ${ }^{27}$ Although pathology often localizes to the RA-AL aponeurosis, injuries more cranial or caudal can also occur, such as tendinosis, tendon tears, adductor myotendinous strains, and avulsions.

Numerous repair techniques have been described that can be grouped into mesh, non-mesh, and adductor-related categories. ${ }^{28}$ Superiority of a particular technique has not been demonstrated with success rates ranging from $85 \%$ to $100 \%{ }^{28}$ Both targeted and nontargeted surgical approaches also seem to provide similar rates of return to play. ${ }^{29}$

\section{Flexor Injuries}

Hip flexor injuries typically refer to pathology of the iliopsoas, rectus femoris, and sartorius. Hockey is the second most common sport to result in a hip flexor injury after soccer, and recurrence is observed in 24 to $31 \%$ of cases. ${ }^{14}$ Similar to rectus-adductor injuries, most flexor injuries are noncontact in mechanism. Injuries include iliopsoas strains and hip snapping that can result in iliopsoas tendinosis and bursitis. ${ }^{30}$ Hip flexors strains seem to occur mainly in highlevel players, which was hypothesized to be due to increased biomechanical recruitment. ${ }^{31}$

Although ultrasonography (US) and MRI can both be used to evaluate the distal tendon of the iliopsoas and proximal rectus femoris, $50 \%$ of clinically diagnosed hip flexor injuries in athletes with groin pain are negative. ${ }^{32}$ Additionally, clinical diagnoses are discordant with imaging findings in up to $40 \%{ }^{32}$ Hip snapping can essentially only be demonstrated with dynamic US maneuvers. Acute strains are better evaluated with MRI ( - Fig. 3 ) because US has a limited ability to visualize the muscle bellies of the iliopsoas muscles. Acute strains involving the iliopsoas and rectus femoris occurred approximately equally in a study of all athletes, and the iliacus was involved alone or in combination with the psoas with nearly all iliopsoas strains. ${ }^{33}$

\section{Osteitis Pubis}

Osteitis pubis (OP) is an overuse condition involving the pubic symphysis, typically diagnosed clinically when the combination of anteromedial groin pain and tenderness over the pubis are present. The changes of OP are considered secondary to an injury of one or more stabilizing structures around the symphysis. OP could also be a compensatory injury associated with femoroacetabular impingement (FAI). ${ }^{34}$ Isolated OP accounts for only 10 to $20 \%$ of athletes with chronic groin pain. ${ }^{24,35}$ Thus it is important to evaluate closely for associated injuries. 

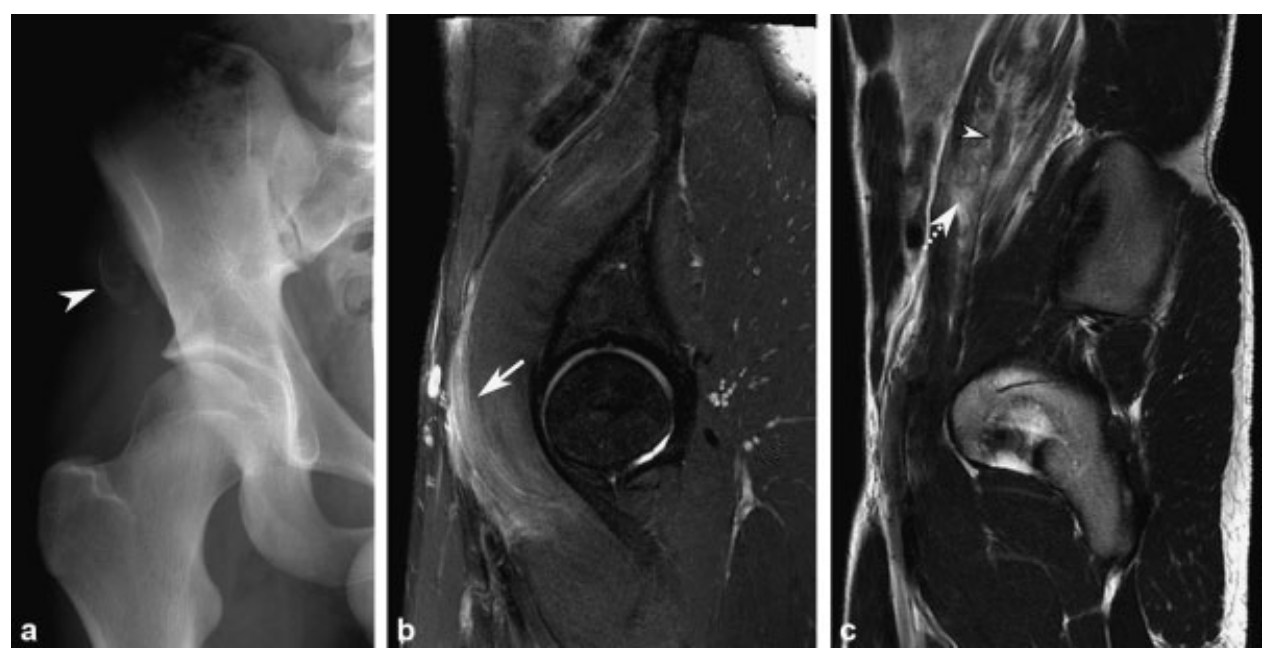

Fig. 3 Flexor injuries in three hockey players. (a) Anteroposterior radiograph of the right hip demonstrates a right anterior superior iliac spine apophyseal avulsion (arrowhead). (b) Sagittal short tau inversion recovery shows feathery edema in the distal iliopsoas muscle in keeping with a strain (solid arrow). (c) Sagittal T2 shows marked edema within the psoas major surrounding the musculotendinous junction (dashed arrow). Wavy appearance of the intramuscular tendon (arrowhead) is in keeping with a high-grade strain, which is associated with delayed return to play.

Bone scintigraphy and radiographs were once the most common imaging modalities used to investigate OP. Hyperemia on the blood flow phase of bone scintigraphy can be recognized before any abnormality is visible on radiographs. ${ }^{36}$ Scintigraphic diagnosis of OP is focal increased radiotracer activity centered in the region of the pubic symphysis on a delayed technetium 99m-methylene diphosphonate bone scan (-Fig. 4a). Radiographic findings of chronic OP are analogous to end-plate changes in spondylosis characterized by osteophytes, joint space narrowing, surface irregularity, subchondral sclerosis, and cysts. Unfortunately, these findings occur in asymptomatic individuals, and their prevalence increases with age. ${ }^{37}$ Flamingo views are a radiographic technique that can demonstrate evidence of symphyseal instability. Symphyseal widening $>7 \mathrm{~mm}$ or malalignment of the super pubic rami cranial cortices $>2$ mm suggest joint laxity, although up to $5 \mathrm{~mm}$ can be seen in asymptomatic patients. 38,39

It is debatable whether MRI can correctly identify symptomatic OP. BME is usually on both sides of the symphysis and involves the entire anteroposterior extent of the joint (-Fig. 4b), which is useful in distinguishing OP from other causes of marrow edema. ${ }^{40}$ BME, symphysis fluid, and periarticular soft tissue edema are findings of acute and subacute OP $(<6 \text { months })^{41}$ and were found to be more associated with pain. ${ }^{42}$ Unfortunately, pubic BME is present in many athletes who are asymptomatic, ${ }^{43,44}$ and pubic BME is not useful in selecting patients for surgical intervention. ${ }^{45,46}$

In most cases, OP is a self-limited source of pain that can be managed conservatively. ${ }^{47}$ Injections of local anesthetic were shown to be effective for diagnostic purposes. ${ }^{24,48}$ Local injections of corticosteroid do not provide lasting relief because multiple injections are often required. However, corticosteroid injections are advantageous when time away from playing is not possible. Surgical options in refractory cases include symphyseal debridement, arthrodesis, and wedge resection. Because many believe OP to be secondary to injuries around the symphysis that result in altered biomechanics, pain due to OP resolves with treatment of the primary injury. In studies in which OP is an isolated abnormality, rehabilitation provides a much faster return to play, and surgery is used as a last resort. ${ }^{49}$

\section{Inguinal Injuries}

Inguinal canal pathology is another possible source of groin pain in athletes. The "sportsman hernia" is described as a posterior inguinal canal wall deficiency. The pathogenesis of a sportsman hernia is controversial. Surgically confirmed external oblique aponeurosis defects/tearing (i.e., anterior canal wall) or laxity of the transversalis fascia (i.e., posterior canal wall) were found in some athletes. ${ }^{50} \mathrm{~A}$ significant source of pain in these patients was believed to be due to the scarring that results in tension/entrapment of the ilioinguinal nerve, a finding seldom visible on MRI. ${ }^{50}$ Others have suggested that injuries to the RA-AL aponeurosis can lead to weakening at the superficial ring and result in the observed posterior wall bulging, given the close proximity of the aforementioned structures. ${ }^{18}$

True inguinal hernias are considered to be an uncommon cause of groin pain in athletes. However, one study found a substantial proportion of hockey players have symptomatic inguinal hernias (nearly all direct) compared with a healthy control group. Indirect hernias were similar in prevalence between symptomatic athletes and asymptomatic controls, suggesting they are unlikely to be a source of pain. ${ }^{51}$

US is the test of choice for evaluating the inguinal region for the sportsman hernia, true hernias, and genitourinary pathology. Sportsman hernia is described as posterior wall bulging elicited by Valsalva that can be demonstrated with US or MRI. ${ }^{52}$ However, this finding was shown to be nonspecific. ${ }^{49}$ In most cases, pathology localizing to the inguinal canal results in a normal MRI. ${ }^{53}$ US is an extremely accurate method of confirming a clinically suspected true hernia, but 


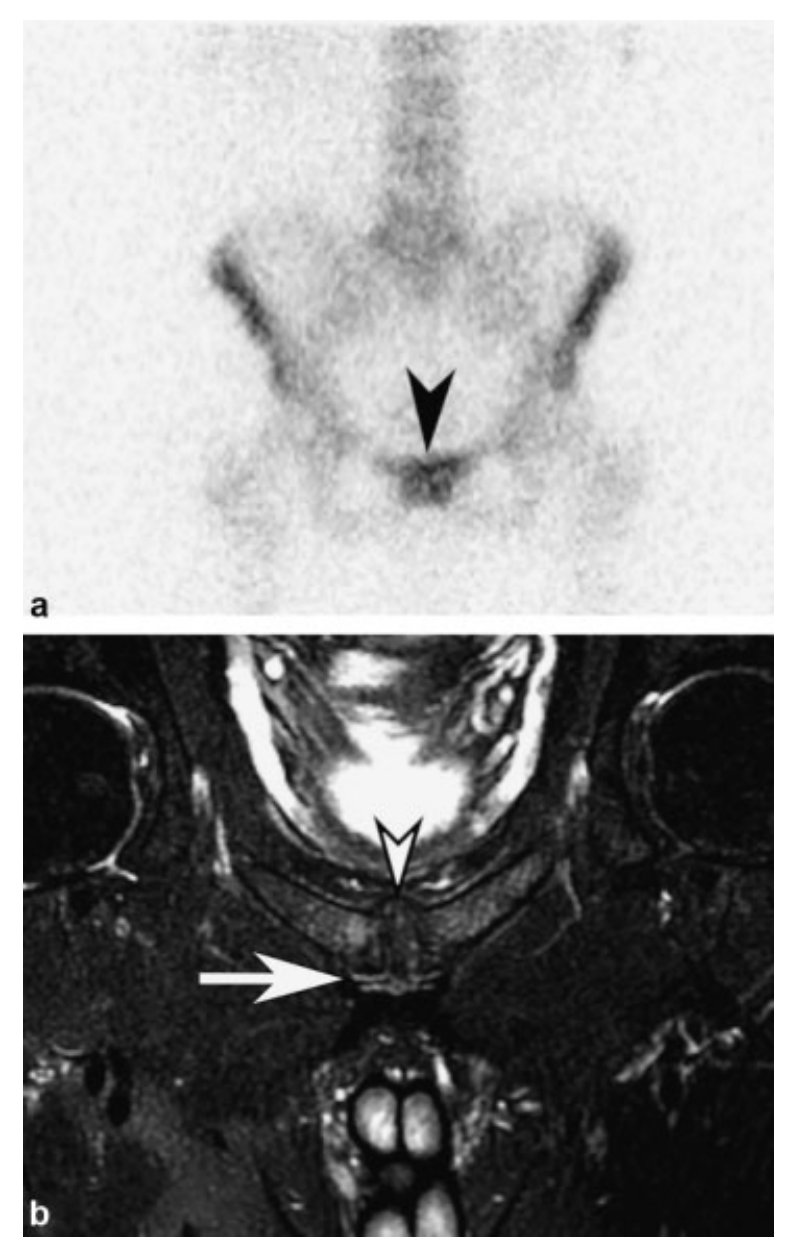

Fig. 4 Hockey player with tender lower rectus and adductors due to osteitis pubis (OP). (a) Anterior projection technetium 99m-methyl diphosphonate delayed acquisition (4 hours) demonstrates increased radiotracer uptake centered on the pubic symphysis (black arrowhead) in keeping with OP. (b) Axial oblique T2-weighted fat-suppressed sequence demonstrates tenoperiosteal tearing of the rectus abdominis-adductor longus aponeurosis to the bilateral pubic bodies (arrow). Bilateral asymmetric pubic body bone marrow edema, osteophytes (arrowhead), and symphysis surface irregularity are findings of OP although secondary to core muscle injury.

in many cases, no definite hernia sac is palpable, and in clinically occult hernias, the specificity of US decreases. ${ }^{54,55}$

\section{Intra-articular: Labral Tears and Femoroacetabular Impingement}

Although intra-articular pathology accounts for only $11 \%$ of hip/groin injuries among professional hockey players, it results in up to seven times greater playing time lost compared with extra-articular injuries. ${ }^{9}$ The most common intra-articular pathologies are labral tears (69\%), osteoarthritis (14\%), loose bodies (6\%), and FAI (5\%). ${ }^{9}$ Imaging plays a vital role in the work-up of hip/groin pain, in general, and identifies an unsuspected etiology in up to $33 \%$ of cases. ${ }^{56}$

The mechanism of labral tears in hockey, similar to other sports, is related to repetitive microtrauma. Some suggest that repetitive traction from the indirect head of the rectus femoris may be contributory. Direct trauma, hip dysplasia, and FAI-type hip morphologies are known causes of labral tears with the latter the most common radiographically in hockey players. ${ }^{57}$ However, FAI-type morphologies do not necessarily result in labral tears and chondromalacia, ${ }^{58}$ and many hockey players with cam morphology are asymptomatic. In one study, $68 \%$ of hockey players had cam or pincer morphology on radiographs; only $22 \%$ of those with abnormal radiographs were symptomatic. ${ }^{59}$ Ice hockey players have the second highest prevalence of cam lesions after soccer players, and, in general, they are more common in male athletes. ${ }^{60}$ Cam morphology can develop at a young age; it is detected up to 15 times more commonly in youth ice hockey players and 4.5 times more commonly in young adults as compared with the general population. ${ }^{61}$ Quantitatively, elite amateurs and professional hockey players have a higher average $\alpha$ angle, ranging from 54 to 62 degrees. $25,27,59-61$

The gold standard for imaging of intra-articular hip pathology is MR arthrography. Morphologic assessment of the femoral head and acetabulum can be performed through various measurements on radiographs, computed tomography or MRI, and the review by Sutter and Pfirrmann provides a detailed description of each. ${ }^{58}$ Labral tears most commonly involve the anterosuperior and posterosuperior labrum. ${ }^{62} \mathrm{~A}$ tear is demonstrated by fluid signal undercutting an intact labrum (i.e., chondrolabral separation) or extending into the substance of the labrum (-Fig. 5). Unfortunately, the two most common asymptomatic intra-articular pathologies are labral tears and osteochondral lesions that have been documented in up to $56 \%$ and $18 \%$ of players, respectively. Asymptomatic hockey players have abnormal hip MRI findings in $64 \%$ of cases. ${ }^{25}$ Although the radiologist has a high pretest probability of identifying a possible pain generator, a sports physician/orthopaedic surgeon is vital to correlate clinically. Response to an intra-articular anesthetic injection at the time of MR arthrography was shown to have a high positive predictive value for intra-articular pathology as a source of pain. ${ }^{63}$

Treatment of FAI with osteochondroplasty remains a practice that varies with each individual surgeon. A recent randomized controlled trial on the treatment of FAI concluded that the main value of osteochondroplasty is the prevention of recurrent hip symptoms. ${ }^{64}$ Hockey is among the sports in which athletes are most likely to undergo bilateral hip arthroscopy. ${ }^{7,65}$ Multiple studies showed that those that undergo arthroscopic treatment have a higher probability (60-100\%) of returning to the same level of play, with a mean postoperative career of 3.3 years. ${ }^{66-68}$

\section{Other Causes}

Direct trauma to the hip can result in muscle contusion around the iliac crest, bone contusion, or subperiosteal edema/hematoma. This injury, is commonly referred to as a hip pointer ${ }^{69}$ and accounts for $2.4 \%$ of all injuries in collegiate hockey. These injuries are clinically diagnosed and usually do not require imaging. Treatment is conservative with physiotherapy focused on hip abduction. ${ }^{30}$

Fractures involving the hip are uncommon in hockey. Stress fractures are very infrequent compared with other sports, ${ }^{70}$ 

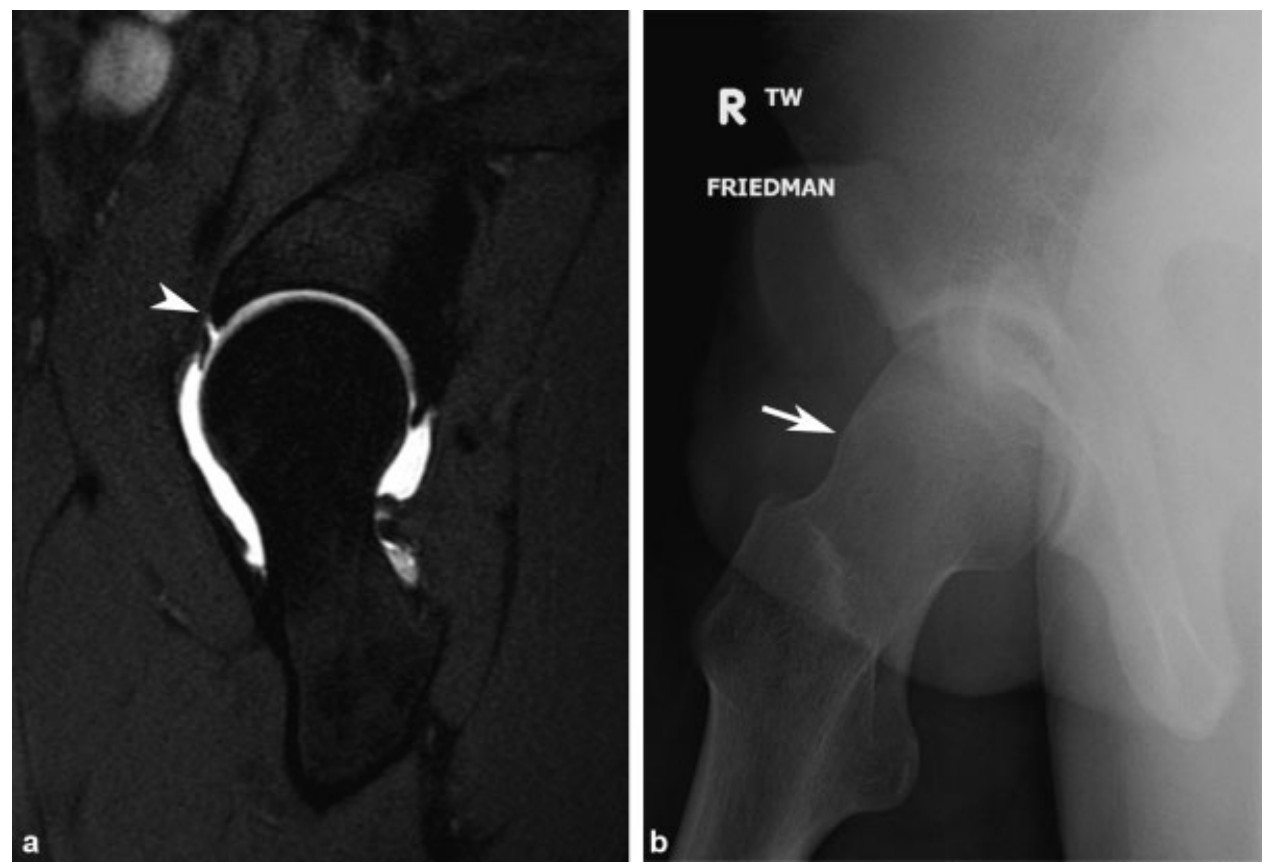

Fig. 5 Labral tear and cam morphology in a young hockey player. (a) Sagittal T1-weighted fat-suppressed sequence with intra-articular contrast demonstrates chondrolabral separation of the anterosuperior labrum (arrowhead). (b) Friedman view radiograph o the right hip shows loss of sphericity of the femoral head at the anterosuperior femoral head-neck junction in keeping with cam morphology (arrow).

although they are very important to recognize. Femoral neck stress reaction/fractures cannot be missed on imaging ( - Fig. 6) because they may require a significant activity level modification to the point of non-weight bearing.

Although non-sport-related pathologies account for a minority of cases of athlete groin pain, visceral, neuropathic, and non-sport-related osseous pathology ( - Fig. 7) should also be considered in the differential diagnosis because radiologists may be the first to suspect and diagnose such entities.

\section{Thigh}

Quadriceps and hamstring injuries are much less common than hip flexor and adductor injuries. ${ }^{71,72}$ Despite padding, the thigh is one of the most common sites of contusion in hockey. ${ }^{73}$ Muscular contusions in contact athletes most often involve the anterior muscles of the quadriceps (i.e., rectus femoris and vastus intermedius). Contusions are often suspected based on history but can also be differentiated from a strain radiologically by these features: (1) overlying subcutaneous edema/hemorrhage, and (2) hematoma located within the muscle belly rather than at the myotendinous junction. On US, muscle contusion appears as ill-defined heterogeneous echogenicity within a muscle belly that obscures its normally visible architecture (-Fig. 8). ${ }^{74}$ On MRI, muscle contusion demonstrates relatively preserved muscle architecture with interstitial hemorrhage, resulting in a feathery appearance on fluid-sensitive sequences. ${ }^{75}$ Quadriceps contusions are managed conservatively, maintaining deep knee flexion for 24 hours using a locked knee brace followed by strengthening and stretching. ${ }^{76}$ Recovery may only require a few days, and therefore minimal playing time lost. 77
Hamstring contusions can also occur but are anecdotally less common in hockey. Ice hockey has one of the lowest incidences of hamstring strains among National Collegiate Athletic Association (NCAA) sports, which are most commonly noncontact in mechanism. ${ }^{72}$

\section{Knee}

\section{General}

Even though shin guards protect the knees from direct trauma, knee injuries are quite prevalent, representing the most common lower extremity injury in hockey. Medial collateral ligament (MCL) injuries, in particular, are the second most common injury after concussions in collegiate-level players and the third most common injury to result in significant time loss from competition. ${ }^{78}$

The knee is put through the full range of motion during fast skating with the optimal stride technique requiring significant knee flexion and near-complete extension. Abrupt changes in direction can result in varus, valgus, and twisting forces that result in the most common injuries around the knee: MCL, meniscal, and anterior cruciate ligament (ACL) tears. ${ }^{1,79,80}$

\section{Collateral Ligament Injuries}

By far, the most common knee ligament injury involves the MCL, accounting for 57 to $67 \%$ of ligamentous knee injuries. ${ }^{1,80}$ MCL injuries have a similar incidence in forward and defense positions. ${ }^{78}$ Many MCL injuries are related to player contact; noncontact injury due to catching an edge only accounts for $15 \%$ of cases. ${ }^{78,81}$

MRI is the definitive imaging study for assessment of MCL injuries that are graded similarly to other ligamentous 


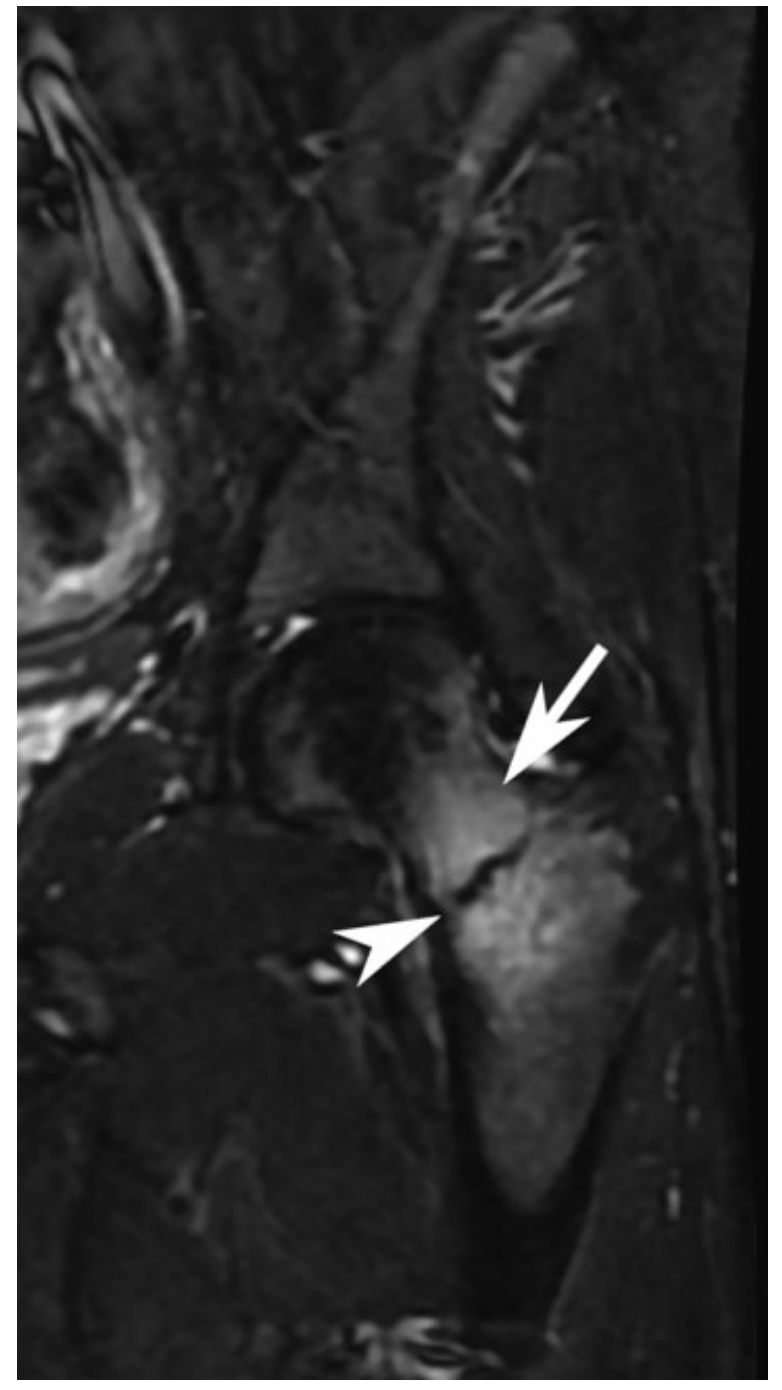

Fig. 6 Left femoral neck stress fracture in a hockey player. Coronal short tau inversion recovery sequence of the left proximal femur shows a linear hypointensity transverse to the basicervical femoral neck (arrowhead) with surrounding bone edema (arrow) in keeping with a stress fracture.

injuries (-Fig. 9). Most MCL tears in hockey are partial tears, with one study reporting grade 1 or 2 injuries in $92 \%$ of cases. ${ }^{78}$ Grade 3 MCL injuries are less often isolated, and therefore a concerted effort to identify other injuries is necessary. It is important to differentiate proximal versus distal locations in grade $3 \mathrm{MCL}$ tears. Distal grade 3 tears can result in a Stener-type lesion that will not heal with conservative management. ${ }^{82}$

Return to play after MCL injury can be correlated with the Hughston modification of the American Medical Association grading $^{83}$ : 0 to 2 weeks for grade $1 ; 2$ to 4 weeks for grade 2 , and 6 to 8 weeks for grade $3 .{ }^{81}$ Grade 2 and 3 injuries often require a hinged knee brace while the ligament is healing. ${ }^{81}$ MCL injuries are treated conservatively in the vast majority of cases; however, some surgeons treat high-grade injuries combined with unstable ACL injuries with reconstruction of both ligaments. $^{84}$

Lateral collateral ligament (LCL) injuries are rare in hockey because direct trauma to the knee usually produces valgus rather than varus stress. ${ }^{81} \mathrm{LCL}$ injuries are important to recognize on imaging because the $\mathrm{LCL}$ complex is unlikely to heal with conservative management and is very important in stabilizing the knee during a hockey stride toward the affected side. Partial LCL tears are managed conservatively with 2 to 3 weeks of bracing. ${ }^{81}$

\section{Cruciate Ligament Injuries}

In hockey, ACL injuries account for $\sim 10 \%$ of ligamentous injuries ${ }^{1}$ and occur by incidental contact or body checking in $66 \%$ of cases. ${ }^{79}$ Forwards are the most likely to sustain an ACL injury, accounting for $70 \%$ of cases. ${ }^{79}$

Classic radiographic signs of ACL injuries are important to recognize, although radiographs are primarily reserved for ruling out osseous injuries. MRI should be performed for any concern of ACL or posterior cruciate ligament (PCL) injury.

The incidence of concurrent injuries in players with $\mathrm{ACL}$ tears differs compared with other sports, which may be related to tears in hockey occurring more commonly via a contact mechanism. BME lesions are less common than expected in ACL injuries, yet they are a common finding in asymptomatic hockey players. ${ }^{85} \mathrm{MCL}(22-40 \%)$, cartilage (10\%), and meniscal injuries (6-23\%) are frequent (-Fig. 10), whereas LCL injuries are rare, similar to other sports. ${ }^{79,86}$ PCL injuries are uncommon in hockey based on our experience.

ACL reconstruction, physiotherapy, and a graded reintroduction of on-ice demands is the treatment pathway for ACL injuries with more than minimal instability or comorbid intra-articular pathology. ${ }^{77,87}$ Hockey is a sport where an isolated ACL injury with minimal instability can be treated conservatively without surgical reconstruction, ${ }^{77,88}$ which may be evidenced by the fact that $9 \%$ of asymptomatic players had an ACL tear in one study. ${ }^{85}$

Studies find hockey players post-ACL reconstruction have higher rates of return to play (96\%), shorter recovery times, and longer postoperative careers compared with athletes in other sports. ${ }^{79,89,90}$ Some studies have found no change in performance ${ }^{89,91}$ while others reported a decrease in goals and points. ${ }^{79}$

\section{Meniscal Injuries}

Meniscal tears account for 5 to $16 \%$ of knee injuries in hockey. ${ }^{80,92}$ These are important to recognize, especially in the setting of ACL tears, because they are associated with shortening of a player's postoperative career ${ }^{93}$ and premature osteoarthritis. ${ }^{94}$ In addition, a meniscal tear is more likely to result in surgical management of other lesions such as an ACL tear. Imaging plays a vital role in the diagnosis of meniscal injuries because the sensitivity of physical examination maneuvers is unacceptably poor.

Although US may be advantageous for point-of-care assessment of the elite athlete with a possible meniscal injury, MRI remains the definitive imaging modality. ${ }^{85,95}$ The International Society of Arthroscopy, Knee Surgery, and Orthopaedic Sports Medicine classification system applied to MRI is the most commonly used system to describe meniscal pathology. It provides an agreed upon lexicon for orthopaedic surgeons and radiologists. ${ }^{96}$ Although not specifically 

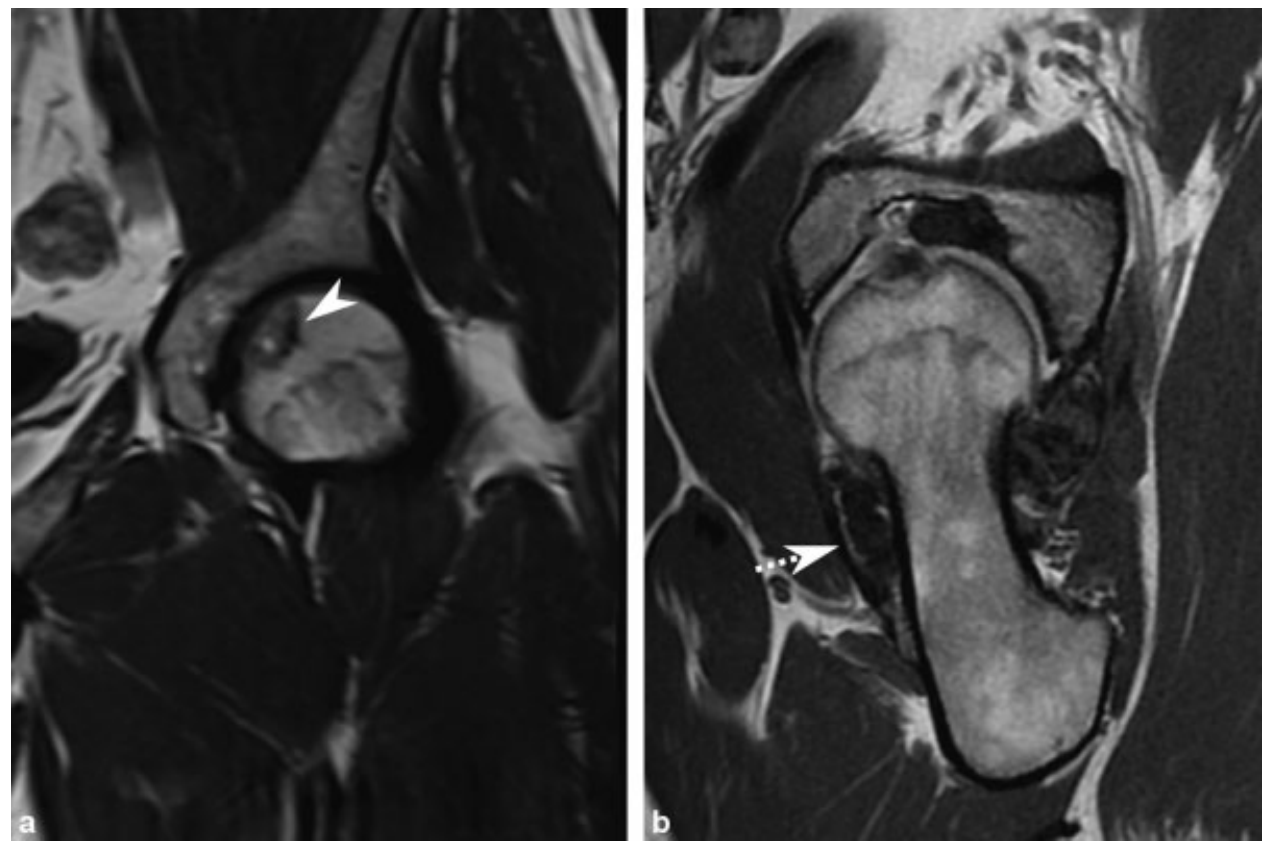

Fig. 7 Unsuspected hip pathologies in two hockey players presenting with hip/groin pain. (a) Left hip coronal T1 demonstrates a geographic anterosuperior subchondral femoral head lesion with hypointense margins (arrowhead) and central fat signal; short tau inversion recovery sequence (not shown) demonstrated an additional inner hyperintense rim creating the "double-line sign" in keeping with avascular necrosis. (b) Left hip oblique axial T1 shows markedly hypointense synovial thickening (dashed arrow) in keeping with pigmented villonodular synovitis.

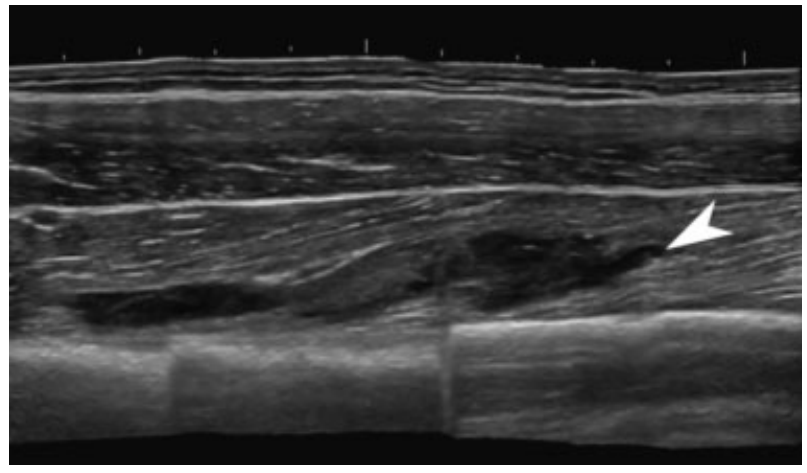

Fig. 8 Vastus intermedius intramuscular hematoma after a direct blow to thigh. Longitudinal gray-scale image demonstrates architectural disruption of the vastus intermedius muscle belly by a heterogeneously hypoechoic collection (arrowhead) in keeping with acute hematoma.

studied in hockey, meniscal injuries in athletes more frequently involve the medial meniscus, which is also true of hockey players at our institution. ${ }^{97}$ Degenerative meniscal signal is present in up to $50 \%$ of asymptomatic hockey players; however, a traumatic pattern of tears is not an incidental finding. 85

Management of meniscal injuries is challenging in athletes because the patient population is young and menisci are very chondroprotective; meniscectomy is a known risk factor for the development of osteoarthritis. ${ }^{98}$ Nonoperative management is considered for stable tears that are likely to heal spontaneously (i.e., in the red zone). The stability of a tear is determined by whether it is displaceable by a probe at arthroscopy. Arthroscopically stable traumatic tears generally correlate with short vertical tears $(<5 \mathrm{~mm})$ on

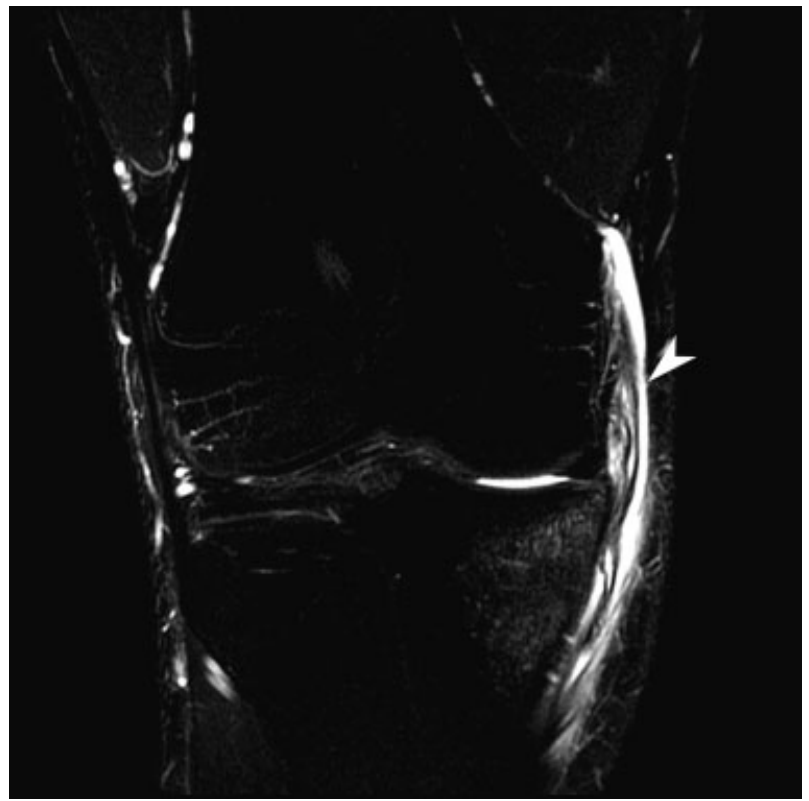

Fig. 9 Medial collateral ligament injuries in two hockey players. Right knee coronal T2-weighted fat-suppressed sequence demonstrates a wavy contour of the medial collateral ligament with severe periligamentous edema (arrowhead) in keeping with a complete tear of the mid to distal portion.

imaging. ${ }^{99,100}$ Repair of tears involving the avascular zone is warranted in young active adults. Good functional outcomes are achieved even despite only partial or nonhealing of the tear. ${ }^{99}$ Partial meniscectomy of irreparable tears does not necessarily equate to early osteoarthritis with adherence to biomechanical principles. In non-hockey sports, 

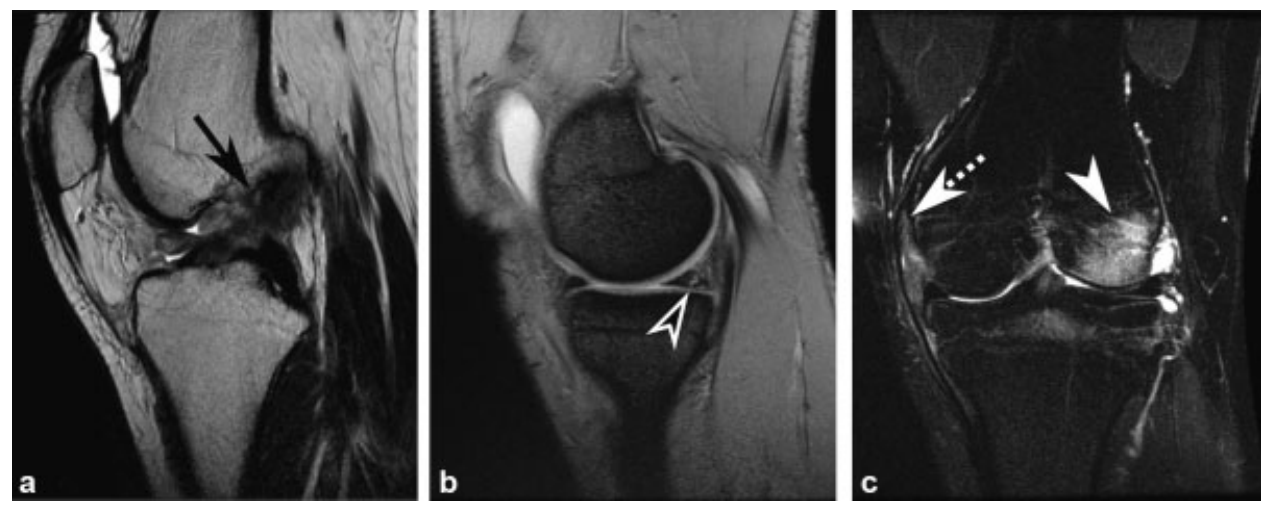

Fig. 10 Internal derangement of the left knee in a young hockey player. (a) Sagittal proton-density (PD) image shows an indistinct appearance of the anterior cruciate ligament with ligamentous laxity and a more horizontal course in keeping with a complete tear (black arrow). (b) Sagittal PD fat-suppressed (FS) sequence through the medial compartment demonstrates a ramp lesion (open arrowhead) in the medial meniscus posterior horn. (c) Coronal T2FS demonstrates lateral femoral condyle bone marrow edema due to impaction on the posterior lateral tibial plateau and a low-grade partial medial collateral ligament tear (dashed arrow).

meniscal repair and meniscectomy have similar rates of return to play. ${ }^{101}$ Meniscal allograft is generally not considered an option in those wanting to continue an athletic career.

\section{Patellofemoral Injuries}

Among NCAA college sports, men's and women's ice hockey has one of the lowest rates of patellofemoral pathology. Patellar tendinosis is an overuse injury and represents the most common patellofemoral pathology in hockey. ${ }^{73,102,103}$ Radiologically, patellar tendinosis is defined by smooth thickening $(>7 \mathrm{~mm}$ ) and abnormal signal within the patellar tendon on MRI and US. ${ }^{104,105}$ Numerous conservative measures are used in the treatment of this common entity, although few have strong evidence of efficacy. ${ }^{106}$

Patella subluxation is the second most common injury, accounting for $33 \%$ of patellofemoral injuries. ${ }^{102}$ The mechanism of instability (subluxation or dislocation) is most commonly noncontact; however, contact resulting in instability is much more common in hockey than most other sports. ${ }^{102}$ MRI findings of patella dislocation include tearing of the medial retinaculum, kissing bone contusions and/or osteochondral fractures of the medial patella and outer lateral femoral condyle (-Fig. 11). Associated injuries of menisci, collateral, or cruciate ligaments are only observed in $6 \%$ of patellofemoral subluxation/dislocation in athletes. $^{102}$

Other common injuries included infra- and prepatellar bursitis. ${ }^{103,107}$ Given the knee protection of hockey equipment, fractures are distinctly uncommon but often require surgery. ${ }^{103,107}$ After patellar fractures, patellar subluxation and dislocation are the two most common injuries to require surgical intervention in athletes and result in $>14$ days of playing time lost. ${ }^{103}$ Although patellofemoral osteoarthritis was not reported in a multi-season assessment of NCAA hockey players, a review of asymptomatic abnormalities detected on knee MRI found that $47 \%$ of players had chondral injuries, primarily in the patellofemoral compartment. $^{85}$

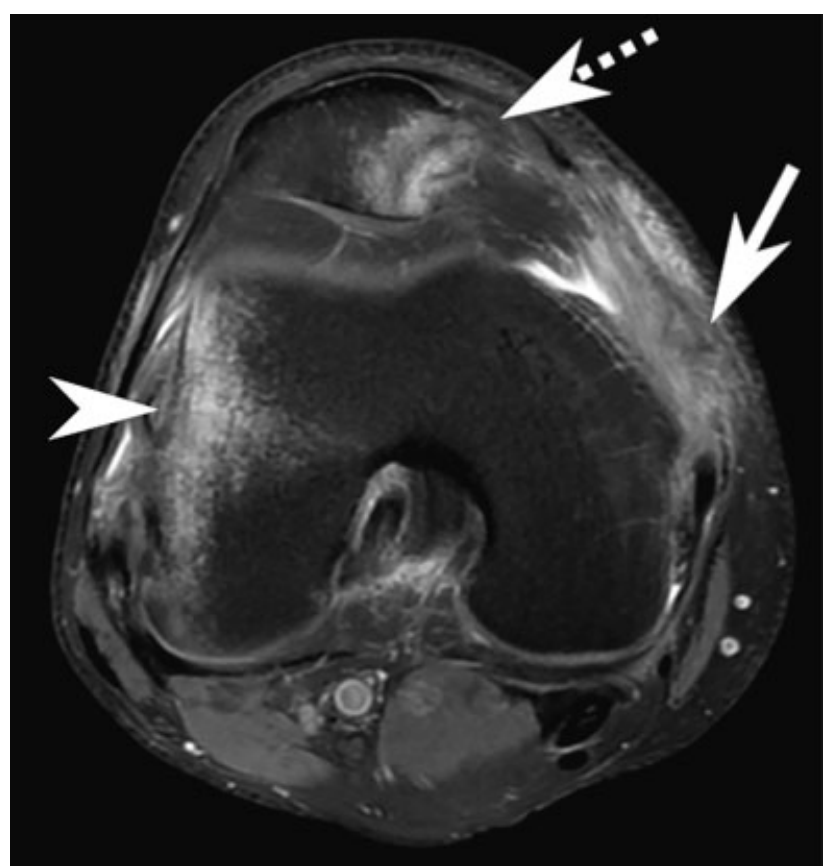

Fig. 11 Patella dislocation with subsequent reduction in a hockey player. Axial PDFS through the right patellofemoral joint shows a kissing contusion pattern involving the medial patella (dashed arrow) and outer cortex of the lateral femoral condyle (arrowhead) with associated impaction fractures. Complete disruption of the medial patellofemoral ligament is indicated by indistinct high signal at its expected location (solid arrow).

\section{Foot and Ankle}

\section{Ligamentous Injuries}

The foot and ankle are the site of $12 \%$ of all hockey injuries. Ankle sprains are the fourth most frequent injury in hockey, ${ }^{1,5}$ and high ankle sprains, in particular, are an exceedingly common injury, accounting for 36 to $74 \%$ of ankle injuries in high-level players. ${ }^{5,108}$ Interestingly, hockey is the most common sport to result in a high ankle sprain ${ }^{109}$ and has one of the lowest incidences of low ankle sprains among 
collegiate sports. ${ }^{110}$ However, this pattern does not seem to hold true for female hockey players, which is without a clear explanation. ${ }^{111}$ By position, low ankle sprains are more common in forward compared with defense and very rare in goaltenders. ${ }^{111}$ High ankle sprains account for most ankle injuries, resulting in significant time loss (average: 41-45 days) as compared with low ankle sprains (average: 1.4 days). $5,108,111,112$

The pathomechanism of high ankle sprains is external rotation of a dorsiflexed ankle, ${ }^{113}$ which occurs following contact with the boards, another player's stick, or a goal post in $50 \%$ of cases. ${ }^{111}$ Multiple factors contribute to the unusually high incidence of high ankle sprains in hockey: (1) a player's elevated position on skates, (2) high speeds, (3) rapid changes in direction, and (4) a stiff skate stabilizing the lower ankle. ${ }^{5}$ Other sports, such as alpine skiing with restricted ankle flexion/extension, have a high preponderance for high ankle injuries as well. ${ }^{114}$

The role of imaging in the management of ankle sprains in hockey players is similar to other sports. MRI is essential for an accurate description of severity and extent of ligamentous injury and provides the best correlation with arthroscopic findings. ${ }^{112}$ In a series of professional hockey players, the anterior inferior tibiofibular ligament was the most commonly injured occuring in 95\% of cases (-Fig. 12). Posterior inferior tibiofibular ligament and anterior talofibular ligament injuries can also occur (43-52\%). ${ }^{112}$ From the NCAA injury database, syndesmotic, lateral complex, and deltoid ligaments are involved in $80 \%, 15 \%$, and $5 \%$ of ligament injuries, respectively. ${ }^{109,110,115}$ Osteochondral injuries are rare likely due to the tibiotalar joint stabilization provided by a skate. ${ }^{112}$

Unfortunately, MRI does not accurately prognosticate return to play following an ankle sprain, ${ }^{108}$ a shortcoming of imaging that was also confirmed in football. ${ }^{116}$ The recommended treatment of syndesmotic injuries is return to sport after 4 to 8 weeks following conservative management of a grade 1 injury. Surgical management of grade 2 and 3 syndesmotic injuries is recommended. ${ }^{117}$ Low ankle sprains are often managed with rehabilitation, and players often return within a few days to 1 week.

\section{Bursitis and Tenosynovitis/Tendonitis}

Other common hockey-related foot and ankle injuries include "lace bite" and plantar fasciitis, accounting for $6 \%$ and $5 \%$ of foot/ankle injuries, respectively. ${ }^{111}$ There is no imaging literature on lace bite, which is diagnosed clinically and likely represents extensor tenosynovitis or tendonitis. It is usually observed early in the season when players are using new skates that have not been broken in, causing excessive anterior friction.

In other skating sports, adventitial bursitis can also result from ill-fitting skates that cause chronic focal pressure and motion of the skin overlying the malleoli. The medial malleolus is more commonly affected than the lateral malleolus (-Fig. 13). This condition is managed conservatively in most cases, but surgical resection is considered if there is superimposed infection. ${ }^{118}$

\section{Fractures}

Lower extremity fractures are reported to be a small proportion (12\%) of all hockey-related fractures. Approximately $45 \%$ of lower extremity fractures involve the tibia or fibula. ${ }^{119} \mathrm{At}$ our institution, we have observed a substantial number of hockey-related ankle fractures. The most common pattern is a fibula spiral fracture at or near the level of the tibiofibular joint, in keeping with a supination-external rotation mechanism, ${ }^{120}$ which is expected given the relatively limited plantar flexion that is possible in a skate.

In an institutional review of 27 players, direct blow by a puck was the most common mechanism of foot injury. ${ }^{121}$ Nondisplaced fractures and microtrabecular fractures were
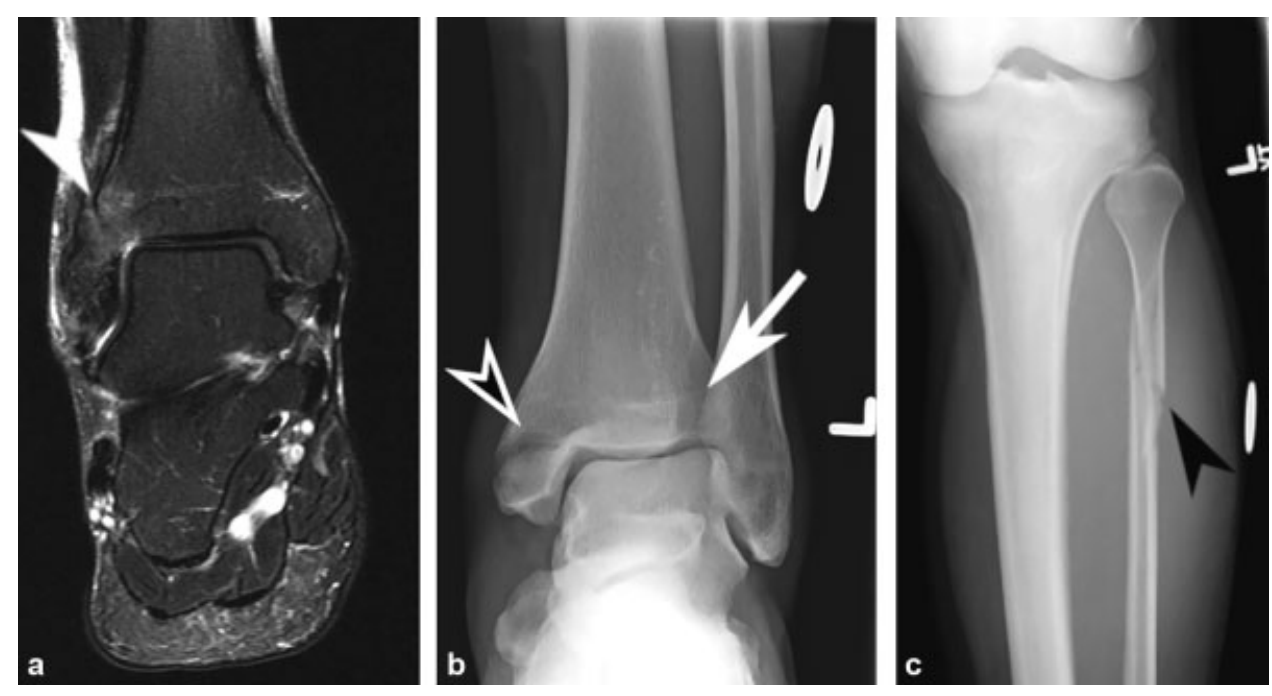

Fig. 12 High ankle injuries in two hockey players (a and b/c). (a) Coronal proton-density fat-suppressed sequence demonstrates indistinct high signal in the expected location of the anteroinferior tibiofibular ligament (white arrowhead). Anteroposterior radiographs of the (b) ankle and (c) leg demonstrate the supination-abduction mechanism of injury with a horizontal fracture of the medial malleolus (open arrowhead), widening of the syndesmotic clear space (arrow), and a proximal fibula fracture (black arrowhead) indicating an extensive syndesmosis injury. 


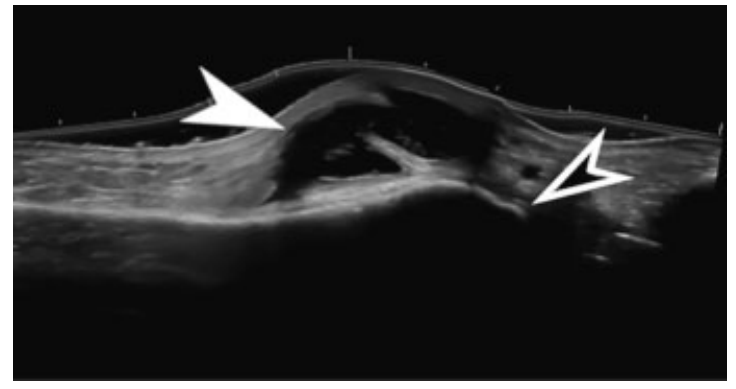

Fig. 13 Skate-induced adventitial bursitis over the medial ankle of a hockey player. Panoramic coronal gray-scale ultrasonographic image of the medial ankle demonstrates an irregular anechoic collection (solid arrowhead) with a thick septation and low-level internal echoes overlying the medial malleolus (open arrowhead) in keeping with adventitial bursitis.
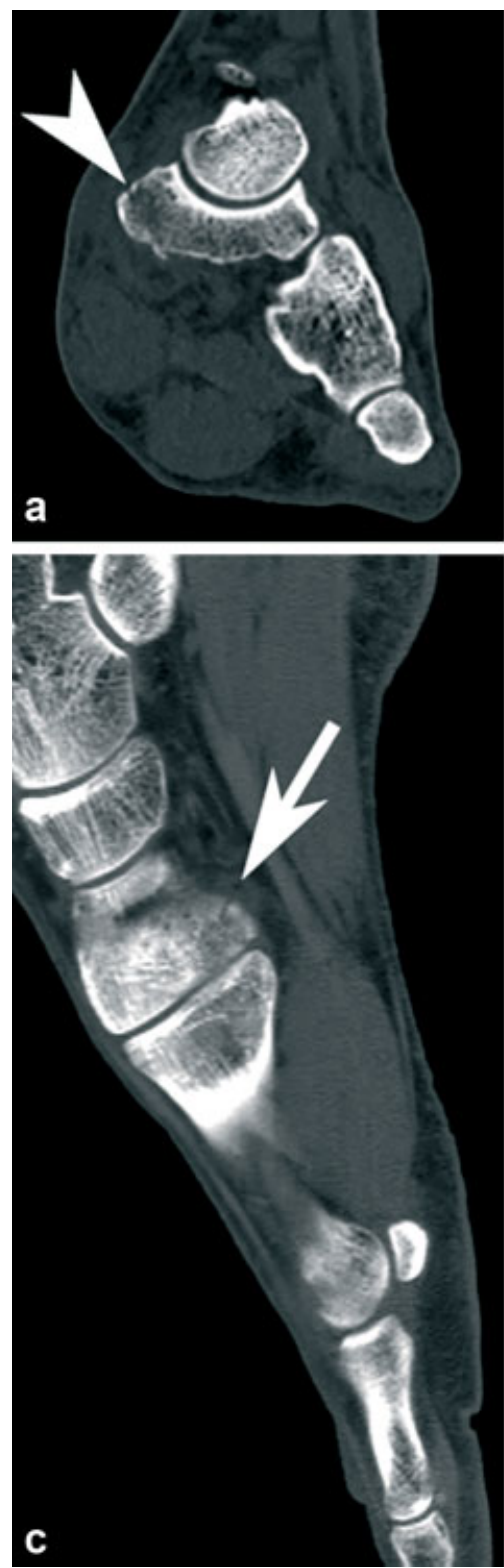

common; with $71 \%$ of bone contusions being high grade. There is a distinct predilection for the medial malleolus, navicular, and first metatarsal base (82\% of fractures) (-Fig. 14). These findings are consistent with players extending their foot to block shots with their instep facing toward their opponent. Not unexpectedly, defensemen are the most frequently injured with this pattern. Players with severe bone injury (occult fracture or high-grade contusion) had longer recovery times. If clinical suspicion is high for an osseous injury, MRI was shown to be valuable in more accurately characterizing radiographically occult pathology of the foot/ankle. ${ }^{121}$

Sequelae of direct trauma (i.e., soft tissue contusions and fractures) are common foot/ankle injuries in hockey players. In fact, the second and third most common foot/ankle injuries are contusions (25-35\%) and fractures (6\%). ${ }^{111}$
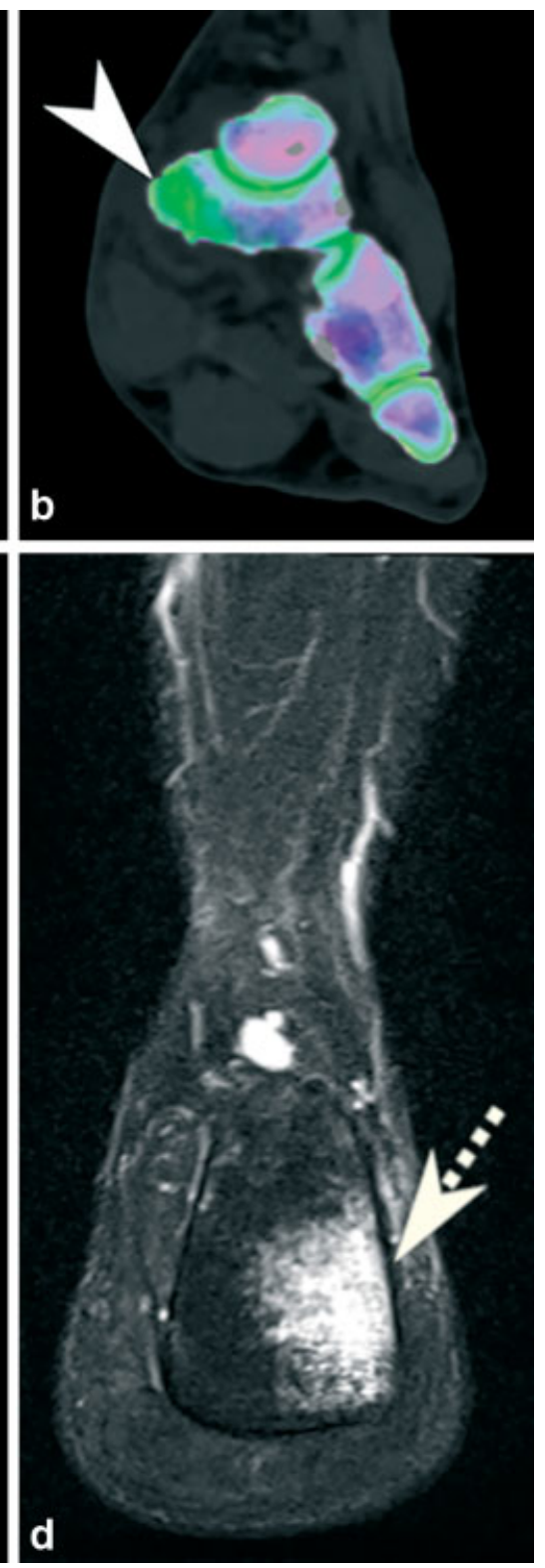

Fig. 14 Foot and ankle fractures occurring following direct trauma by a hockey puck in three hockey players (a/b, c, and d). (a) Coronal dual-energy computed tomography (CT) and (b) bone marrow edema (BME) map overlay of the left navicular demonstrate a nondisplaced fracture of the navicular tuberosity with associated focal BME (arrowhead). (c) Sagittal CT demonstrates a nondisplaced fracture (solid arrow) of the distal plantar aspect of the medial cuneiform. (d) Coronal T2-weighted fat-suppressed sequence of the ankle shows a severe bone contusion (dashed arrow) involving the calcaneus posterior tuberosity. 
Fortunately, foot/toe contusions rarely result in lost playing time. Construction of skates has changed over the years to make them lighter for performance, but this change may have decreased their protective capacity. ${ }^{121}$

\section{Conclusion}

Despite advances in equipment, recreational and professional hockey players remain at a high risk of traumatic and overuse injury. A knowledge of sport-specific injury epidemiology is useful for the radiologist because it allows more subtle radiologic abnormalities to be identified that would have otherwise gone undetected. This is especially true for groin pain that has an extensive differential and relies heavily on imaging to make a specific diagnosis. Radiologists should have a low threshold to offer cross-sectional modalities in the work-up of hockey players regardless of the site of injury, given their high pretest probability of pathology.

\section{Conflict of Interest}

None declared.

\section{References}

1 Tuominen M, Stuart MJ, Aubry M, Kannus P, Parkkari J. Injuries in men's international ice hockey: a 7-year study of the International Ice Hockey Federation Adult World Championship Tournaments and Olympic Winter Games. Br J Sports Med 2015;49(01): 30-36

2 Agel J, Dompier TP, Dick R, Marshall SW. Descriptive epidemiology of collegiate men's ice hockey injuries: National Collegiate Athletic Association Injury Surveillance System, 1988-1989 through 2003-2004. J Athl Train 2007;42(02):241-248

3 Donaldson L, Li B, Cusimano MD. Economic burden of time lost due to injury in NHL hockey players. Inj Prev 2014;20(05): 347-349

4 Ayeni OR, Kowalczuk M, Farag J, et al. Trends in reporting of mechanisms and incidence of hip injuries in males playing minor ice hockey in Canada: a cross-sectional study. Open Access J Sports Med 2014;5:143-149

5 Flik K, Lyman S, Marx RG. American collegiate men's ice hockey: an analysis of injuries. Am J Sports Med 2005;33(02):183-187

6 Emery CA, Meeuwisse WH, Powell JW. Groin and abdominal strain injuries in the National Hockey League. Clin J Sport Med 1999;9(03):151-156

7 Cruz CA, Kerbel Y, Smith CM, Prodromo J, Trojan JD, Mulcahey MK. A sport-specific analysis of the epidemiology of hip injuries in National Collegiate Athletic Association athletes from 2009 to 2014. Arthroscopy 2019;35(09):2724-2732

8 Wörner T, Thorborg K, Eek F. High prevalence of hip and groin problems in professional ice hockey players, regardless of playing position. Knee Surg Sports Traumatol Arthrosc 2020;28(07): 2302-2308

9 Epstein DM, McHugh M, Yorio M, Neri B. Intra-articular hip injuries in national hockey league players: a descriptive epidemiological study. Am J Sports Med 2013;41(02):343-348

10 Jonsson J, Jonsson M, Tegner Y. The epidemiology of overuse injuries in ice hockey: an analysis from 29 seasons in the Swedish Elite League. Open Access J Ortho Sports Med 2019;2(04): 184-188

11 Bisciotti GN, Volpi P, Zini R, et al. Groin Pain Syndrome Italian Consensus Conference on terminology, clinical evaluation and imaging assessment in groin pain in athlete. BMJ Open Sport Exerc Med 2016;2(01):e000142
12 Weir A, Brukner P, Delahunt E, et al. Doha agreement meeting on terminology and definitions in groin pain in athletes. $\mathrm{Br} \mathrm{J}$ Sports Med 2015;49(12):768-774

13 Kai B, Lee KD, Andrews G, Wilkinson M, Forster BB. Puck to pubalgia: imaging of groin pain in professional hockey players. Can Assoc Radiol J 2010;61(02):74-79

14 Eckard TG, Padua DA, Dompier TP, Dalton SL, Thorborg K, Kerr ZY. Epidemiology of hip flexor and hip adductor strains in National Collegiate Athletic Association athletes, 2009/2010-2014/2015. Am J Sports Med 2017;45(12):2713-2722

15 de Koning JJ, de Groot G, van Ingen Schenau GJ. Coordination of leg muscles during speed skating. J Biomech 1991;24(02): 137-146

16 Stull JD, Philippon MJ, LaPrade RF. "At-risk" positioning and hip biomechanics of the Peewee ice hockey sprint start. Am J Sports Med 2011;39(Suppl):29S-35S

17 Chang R, Turcotte R, Pearsall D. Hip adductor muscle function in forward skating. Sports Biomech 2009;8(03):212-222

18 Zoga AC, Mullens FE, Meyers WC. The spectrum of MR imaging in athletic pubalgia. Radiol Clin North Am 2010;48(06):1179-1197

19 Pesquer L, Reboul G, Silvestre A, Poussange N, Meyer P, Dallaudière $B$. Imaging of adductor-related groin pain. Diagn Interv Imaging 2015;96(09):861-869

20 Falvey ÉC, King E, Kinsella S, Franklyn-Miller A. Athletic groin pain (part 1): a prospective anatomical diagnosis of 382 patients -clinical findings, MRI findings and patient-reported outcome measures at baseline. Br J Sports Med 2016;50(07):423-430

21 Brennan D, O'Connell MJ, Ryan M, et al. Secondary cleft sign as a marker of injury in athletes with groin pain: MR image appearance and interpretation. Radiology 2005;235(01):162-167

22 Murphy G, Foran P, Murphy D, Tobin O, Moynagh M, Eustace S. "Superior cleft sign" as a marker of rectus abdominus/adductor longus tear in patients with suspected sportsman's hernia. Skeletal Radiol 2013;42(06):819-825

23 Paajanen $\mathrm{H}$, Hermunen $\mathrm{H}$, Ristolainen L, Branci S. Long-standing groin pain in contact sports: a prospective case-control and MRI study. BMJ Open Sport Exerc Med 2019;5(01):e000507

24 Byrne CA, Bowden DJ, Alkhayat A, Kavanagh EC, Eustace SJ. Sports-related groin pain secondary to symphysis pubis disorders: correlation between MRI findings and outcome after fluoroscopy-guided injection of steroid and local anesthetic. AJR Am J Roentgenol 2017;209(02):380-388

25 Silvis ML, Mosher TJ, Smetana BS, et al. High prevalence of pelvic and hip magnetic resonance imaging findings in asymptomatic collegiate and professional hockey players. Am J Sports Med 2011;39(04):715-721

26 Heerey JJ, Kemp JL, Mosler AB, et al. What is the prevalence of imaging-defined intra-articular hip pathologies in people with and without pain? A systematic review and meta-analysis. $\mathrm{Br} \mathrm{J}$ Sports Med 2018;52(09):581-593

27 Gallo RA, Silvis ML, Smetana B, et al. Asymptomatic hip/groin pathology identified on magnetic resonance imaging of professional hockey players: outcomes and playing status at 4 years' follow-up. Arthroscopy 2014;30(10):1222-1228

28 Zuckerbraun BS, Cyr AR, Mauro CS. Groin pain syndrome known as sports hernia: a review. JAMA Surg 2020;155(04):340-348

29 Kajetanek C, Benoît O, Granger B, et al. Athletic pubalgia: return to play after targeted surgery. Orthop Traumatol Surg Res 2018; 104(04):469-472

30 Kuhn AW, Noonan BC, Kelly BT, Larson CM, Bedi A. The hip in ice hockey: a current concepts review. Arthroscopy 2016;32(09): 1928-1938

31 Buckeridge E, LeVangie MC, Stetter B, Nigg SR, Nigg BM. An on-ice measurement approach to analyse the biomechanics of ice hockey skating. PLoS One 2015;10(05):e0127324

32 Serner A, Tol JL, Jomaah N, et al. Diagnosis of acute groin injuries: a prospective study of 110 athletes. Am J Sports Med 2015;43 (08):1857-1864 
33 Serner A, Weir A, Tol JL, et al. Characteristics of acute groin injuries in the hip flexor muscles-a detailed MRI study in athletes. Scand J Med Sci Sports 2018;28(02):677-685

34 Krishnamoorthy VP, Kunze KN, Beck EC, et al. Radiographic prevalence of symphysis pubis abnormalities and clinical outcomes in patients with femoroacetabular impingement syndrome. Am J Sports Med 2019;47(06):1467-1472

35 Cunningham PM, Brennan D, O'Connell M, MacMahon P, O'Neill $\mathrm{P}$, Eustace S. Patterns of bone and soft-tissue injury at the symphysis pubis in soccer players: observations at MRI. AJR Am J Roentgenol 2007;188(03):W291-W296

36 Briggs RC, Kolbjornsen PH, Southall RC. Osteitis pubis, Tc-99m MDP, and professional hockey players. Clin Nucl Med 1992;17 (11):861-863

37 Branci S, Thorborg K, Nielsen MB, Hölmich P. Radiological findings in symphyseal and adductor-related groin pain in athletes: a critical review of the literature. Br J Sports Med 2013;47(10):611-619

38 Williams PR, Thomas DP, Downes EM. Osteitis pubis and instability of the pubic symphysis. When nonoperative measures fail. Am J Sports Med 2000;28(03):350-355

39 Garras DN, Carothers JT, Olson SA. Single-leg-stance (flamingo) radiographs to assess pelvic instability: how much motion is normal? J Bone Joint Surg Am 2008;90(10):2114-2118

40 Gibbon WW, Hession PR. Diseases of the pubis and pubic symphysis: MR imaging appearances. AJR Am J Roentgenol 1997;169(03):849-853

41 Kunduracioglu B, Yilmaz C, Yorubulut M, Kudas S. Magnetic resonance findings of osteitis pubis. J Magn Reson Imaging 2007;25(03):535-539

42 Gaudino F, Spira D, Bangert Y, et al. Osteitis pubis in professional football players: MRI findings and correlation with clinical outcome. Eur J Radiol 2017;94:46-52

43 Paajanen $\mathrm{H}$, Hermunen $\mathrm{H}$, Karonen J. Effect of heavy training in contact sports on MRI findings in the pubic region of asymptomatic competitive athletes compared with non-athlete controls. Skeletal Radiol 2011;40(01):89-94

44 Lovell G, Galloway H, Hopkins W, Harvey A. Osteitis pubis and assessment of bone marrow edema at the pubic symphysis with MRI in an elite junior male soccer squad. Clin J Sport Med 2006;16(02): 117-122

45 Kuikka L, Hermunen H, Paajanen H. Effect of pubic bone marrow edema on recovery from endoscopic surgery for athletic pubalgia. Scand J Med Sci Sports 2015;25(01):98-103

46 Paajanen H, Hermunen H, Karonen J. Pubic magnetic resonance imaging findings in surgically and conservatively treated athletes with osteitis pubis compared to asymptomatic athletes during heavy training. Am J Sports Med 2008;36(01):117-121

47 Cheatham SW, Kolber MJ, Shimamura KK. The effectiveness of nonoperative rehabilitation programs for athletes diagnosed with osteitis pubis. J Sport Rehabil 2016;25(04):399-403

48 Via AG, Frizziero A, Finotti P, Oliva F, Randelli F, Maffulli N. Management of osteitis pubis in athletes: rehabilitation and return to training-a review of the most recent literature. Open Access J Sports Med 2018;10:1-10

49 King E, Ward J, Small L, Falvey E, Franklyn-Miller A. Athletic groin pain: a systematic review and meta-analysis of surgical versus physical therapy rehabilitation outcomes. Br J Sports Med 2015; 49(22):1447-1451

50 Brown RA, Mascia A, Kinnear DG, Lacroix V, Feldman L, Mulder DS. An 18-year review of sports groin injuries in the elite hockey player: clinical presentation, new diagnostic imaging, treatment, and results. Clin J Sport Med 2008;18(03):221-226

51 Vasileff WK, Nekhline M, Kolowich PA, Talpos GB, Eyler WR, van Holsbeeck M. Inguinal hernia in athletes: role of dynamic ultrasound. Sports Health 2017;9(05):414-421

52 Daigeler A, Belyaev O, Pennekamp WH, et al. MRI findings do not correlate with outcome in athletes with chronic groin pain. J Sports Sci Med 2007;6(01):71-76
53 Branci S, Robinson P. Imaging in long-standing groin pain in athletes. Accessed March 7, 2020 at: https://www.aspetar.com/journal/viewarticle.aspx?id=155\#.XmQQOpNKgxE

54 Kwee RM, Kwee TC. Ultrasonography in diagnosing clinically occult groin hernia: systematic review and meta-analysis. Eur Radiol 2018;28(11):4550-4560

55 Robinson A, Light D, Nice C. Meta-analysis of sonography in the diagnosis of inguinal hernias. J Ultrasound Med 2013;32(02): 339-346

56 Neiman M, Halshtok Neiman O, Aharoni D, Liberman B, Adar E, Eshed I. Magnetic resonance arthrography of the hip: prevalence of diagnoses not suspected by the referring physician and correlation with clinical examination and pain score. Acta Radiol 2016;57(05):595-601

57 Larson CM, Ross JR, Kuhn AW, et al. Radiographic hip anatomy correlates with range of motion and symptoms in National Hockey League players. Am J Sports Med 2017;45(07): 1633-1639

58 Sutter R, Pfirrmann CWA. Update on femoroacetabular impingement: what is new, and how should we assess it? Semin Musculoskelet Radiol 2017;21(05):518-528

59 Brunner R, Maffiuletti NA, Casartelli NC, et al. Prevalence and functional consequences of femoroacetabular impingement in young male ice hockey players. Am J Sports Med 2016;44(01): 46-53

60 Knapik DM, Gaudiani MA, Camilleri BE, Nho SJ, Voos JE, Salata MJ. Reported prevalence of radiographic cam deformity based on sport: a systematic review of the current literature. Orthop J Sports Med 2019;7(032325967119830873

61 Siebenrock KA, Kaschka I, Frauchiger L, Werlen S, Schwab JM. Prevalence of cam-type deformity and hip pain in elite ice hockey players before and after the end of growth. Am J Sports Med 2013;41(10):2308-2313

62 Sutter R, Zubler V, Hoffmann A, et al. Hip MRI: how useful is intraarticular contrast material for evaluating surgically proven lesions of the labrum and articular cartilage? AJR Am J Roentgenol 2014;202(01):160-169

63 Kheterpal AB, Bunnell KM, Husseini JS, et al. Value of response to anesthetic injection during hip MR arthrography to differentiate between intra- and extra-articular pathology. Skeletal Radiol 2020;49(04):555-561

64 Ayeni OR, Karlsson J, Heels-Ansdell D, et al; Femoroacetabular Impingement Randomized Controlled Trial (FIRST) Investigators. Osteochondroplasty and labral repair for the treatment of young adults with femoroacetabular impingement: a randomized controlled trial. Am J Sports Med 2021;49(01):25-34

65 Nawabi DH, Bedi A, Tibor LM, Magennis E, Kelly BT. The demographic characteristics of high-level and recreational athletes undergoing hip arthroscopy for femoroacetabular impingement: a sports-specific analysis. Arthroscopy 2014;30 (03):398-405

66 Philippon M, Schenker M, Briggs K, Kuppersmith D. Femoroacetabular impingement in 45 professional athletes: associated pathologies and return to sport following arthroscopic decompression. Knee Surg Sports Traumatol Arthrosc 2007;15(07): 908-914

67 Philippon MJ, Weiss DR, Kuppersmith DA, Briggs KK, Hay CJ. Arthroscopic labral repair and treatment of femoroacetabular impingement in professional hockey players. Am J Sports Med 2010;38(01):99-104

68 Sochacki KR, Jack RA, Hirase T, Vickery J, Harris JD. Performance and return to sport after hip arthroscopy for femorocetabular impingement syndrome in National Hockey League players. J Hip Preserv Surg 2019;6(03):234-240

69 Hall M, Anderson J. Hip pointers. Clin Sports Med 2013;32(02): 325-330

70 Rizzone KH, Ackerman KE, Roos KG, Dompier TP, Kerr ZY. The epidemiology of stress fractures in collegiate student-athletes, 
2004-2005 through 2013-2014 academic years. J Athl Train 2017;52(10):966-975

71 Eckard TG, Kerr ZY, Padua DA, Djoko A, Dompier TP. Epidemiology of quadriceps strains in National Collegiate Athletic Association athletes, 2009-2010 through 2014-2015. J Athl Train 2017; 52(05):474-481

72 Dalton SL, Kerr ZY, Dompier TP. Epidemiology of hamstring strains in 25 NCAA sports in the 2009-2010 to 2013-2014 academic years. Am J Sports Med 2015;43(11):2671-2679

73 Lorentzon R, Wedrèn H, Pietilä T Incidence, nature, and causes of ice hockey injuries. A three-year prospective study of a Swedish elite ice hockey team. Am J Sports Med 1988;16(04): 392-396

74 Lee JC, Healy J. Sonography of lower limb muscle injury. AJR Am J Roentgenol 2004;182(02):341-351

75 Flores DV, Mejía Gómez C, Estrada-Castrillón M, Smitaman E, Pathria MN. MR imaging of muscle trauma: anatomy, biomechanics, pathophysiology, and imaging appearance. Radiographics 2018;38(01):124-148

76 Irvine JN Jr, Lynch S, Hanypsiak BT, Popkin CA. Lower extremity injuries in ice hockey: current concepts. Am J Orthop 2018;47 (11):

77 Laprade RF, Surowiec RK, Sochanska AN, et al. Epidemiology, identification, treatment and return to play of musculoskeletalbased ice hockey injuries. Br J Sports Med 2014;48(01):4-10

78 Grant JA, Bedi A, Kurz J, Bancroft R, Miller BS. Incidence and injury characteristics of medial collateral ligament injuries in male collegiate ice hockey players. Sports Health 2013;5(03): 270-272

79 Longstaffe R, Leiter J, MacDonald P. Anterior cruciate ligament injuries in the National Hockey League: epidemiology and performance impact. Clin J Sport Med 2020;30(03):224-230

80 Mölsä J, Airaksinen O, Näsman O, Torstila I. Ice hockey injuries in Finland. A prospective epidemiologic study. Am J Sports Med 1997;25(04):495-499

81 LaPrade RF, Wijdicks CA, Griffith CJ. Division I intercollegiate ice hockey team coverage. Br J Sports Med 2009;43(13):1000-1005

82 Robins AJ, Newman AP, Burks RT. Postoperative return of motion in anterior cruciate ligament and medial collateral ligament injuries. The effect of medial collateral ligament rupture location. Am J Sports Med 1993;21(01):20-25

83 Hughston JC. The importance of the posterior oblique ligament in repairs of acute tears of the medial ligaments in knees with and without an associated rupture of the anterior cruciate ligament. Results of long-term follow-up. J Bone Joint Surg Am 1994;76 (09):1328-1344

84 Elkin JL, Zamora E, Gallo RA. Combined anterior cruciate ligament and medial collateral ligament knee injuries: anatomy, diagnosis, management recommendations, and return to sport. Curr Rev Musculoskelet Med 2019;12(02):239-244

85 Chang X-D, Yang P, Mu X-Y, Ma W-L, Zhou M. Evaluation of knees in asymptomatic amateur ice hockey players using 3.0-T magnetic resonance imaging: a case-control study. Chin Med J (Engl) 2018;131(09):1038-1044

86 Kluczynski MA, Kang JV, Marzo JM, Bisson LJ. Magnetic resonance imaging and intra-articular findings after anterior cruciate ligament injuries in ice hockey versus other sports. Orthop J Sports Med 2016;4(05):2325967116646534

87 Capin JJ, Behrns W, Thatcher K, Arundale A, Smith AH, SnyderMackler L. On-ice return-to-hockey progression after anterior cruciate ligament reconstruction. J Orthop Sports Phys Ther 2017;47(05):324-333

88 Moslener MD, Wadsworth LT. Ice hockey: a team physician's perspective. Curr Sports Med Rep 2010;9(03):134-138

89 Erickson BJ, Harris JD, Cole BJ, et al. Performance and return to sport after anterior cruciate ligament reconstruction in National Hockey League players. Orthop J Sports Med 2014;2 (092325967114548831
90 Mai HT, Chun DS, Schneider AD, et al. Performance-based outcomes after anterior cruciate ligament reconstruction in professional athletes differ between sports. Am J Sports Med 2017;45 (10):2226-2232

91 Sikka R, Kurtenbach C, Steubs JT, Boyd JL, Nelson BJ. Anterior cruciate ligament injuries in professional hockey players. Am J Sports Med 2016;44(02):378-383

92 Mitchell J, Graham W, Best TM, et al. Epidemiology of meniscal injuries in U.S. high school athletes from 2007/08-2012/13. Knee Surg Sports Traumatol Arthrosc 2016;24(03):715-722

93 Flint JH, Wade AM, Giuliani J, Rue J-P. Defining the terms acute and chronic in orthopaedic sports injuries: a systematic review. Am J Sports Med 2014;42(01):235-241

94 Konan S, Rayan F, Haddad FS. Do physical diagnostic tests accurately detect meniscal tears? Knee Surg Sports Traumatol Arthrosc 2009;17(07):806-811

95 Xia XP, Chen HL, Zhou B. Ultrasonography for meniscal injuries in knee joint: a systematic review and meta-analysis. J Sports Med Phys Fitness 2016;56(10):1179-1187

96 Wadhwa V, Omar H, Coyner K, Khazzam M, Robertson W, Chhabra A. ISAKOS classification of meniscal tears-illustration on 2D and 3D isotropic spin echo MR imaging. Eur J Radiol 2016; 85(01):15-24

97 Majewski M, Susanne H, Klaus S. Epidemiology of athletic knee injuries: a 10-year study. Knee 2006;13(03):184-188

98 Lie MM, Risberg MA, Storheim K, Engebretsen L, Øiestad BE. What's the rate of knee osteoarthritis 10 years after anterior cruciate ligament injury? An updated systematic review. Br J Sports Med 2019;53(18):1162-1167

99 Giuliani JR, Burns TC, Svoboda SJ, Cameron KL, Owens BD. Treatment of meniscal injuries in young athletes. J Knee Surg 2011;24(02):93-100

100 Kopf S, Beaufils P, Hirschmann MT, et al. Management of traumatic meniscus tears: the 2019 ESSKA meniscus consensus. Knee Surg Sports Traumatol Arthrosc 2020;28(04):1177-1194

101 Ekhtiari S, Khan M, Kirsch JM, Thornley P, Larson CM, Bedi A. Most elite athletes return to competition following operative management of meniscal tears: a systematic review. J ISAKOS 2018;3(02):110-115

102 Mitchell J, Magnussen RA, Collins CL, et al. Epidemiology of patellofemoral instability injuries among high school athletes in the United States. Am J Sports Med 2015;43(07):1676-1682

103 Trojan JD, Treloar JA, Smith CM, Kraeutler MJ, Mulcahey MK. Epidemiological patterns of patellofemoral injuries in collegiate athletes in the United States from 2009 to 2014. Orthop J Sports Med 2019;7(042325967119840712

104 Carr JC, Hanly S, Griffin J, Gibney R. Sonography of the patellar tendon and adjacent structures in pediatric and adult patients. AJR Am J Roentgenol 2001;176(06):1535-1539

105 el-Khoury GY, Wira RL, Berbaum KS, Pope TL Jr, Monu JU. MR imaging of patellar tendinitis. Radiology 1992;184(03):849-854

106 Reinking MF. Current concepts in the treatment of patellar tendinopathy. Int J Sports Phys Ther 2016;11(06):854-866

107 Sproule JR. Hockey injuries. Can Fam Physician 1988; 34:125-129

108 Wright RW, Barile RJ, Surprenant DA, Matava MJ. Ankle syndesmosis sprains in National Hockey League players. Am J Sports Med 2004;32(08):1941-1945

109 Mauntel TC, Wikstrom EA, Roos KG, Djoko A, Dompier TP, Kerr ZY. The epidemiology of high ankle sprains in National Collegiate Athletic Association sports. Am J Sports Med 2017;45(09): 2156-2163

110 Roos KG, Kerr ZY, Mauntel TC, Djoko A, Dompier TP, Wikstrom EA. The epidemiology of lateral ligament complex ankle sprains in National Collegiate Athletic Association Sports. Am J Sports Med 2017;45(01):201-209

111 Crowley SG, Trofa DP, Vosseller JT, et al. Epidemiology of foot and ankle injuries in National Collegiate Athletic Association men's 
and women's ice hockey. Orthop J Sports Med 2019;7(08): 2325967119865908

112 Mollon B, Wasserstein D, Murphy GM, White LM, Theodoropoulos J. High ankle sprains in professional ice hockey players: prognosis and correlation between magnetic resonance imaging patterns of injury and return to play. Orthop J Sports Med 2019;7 (09):2325967119871578

113 Lin C-F, Gross ML, Weinhold P. Ankle syndesmosis injuries: anatomy, biomechanics, mechanism of injury, and clinical guidelines for diagnosis and intervention. J Orthop Sports Phys Ther 2006;36(06):372-384

114 Fritschy D. A rare injury of the ankle in competition skiers. [in French]. Schweiz Z Med Traumatol 1994;(01):13-16

115 Kopec TJ, Hibberd EE, Roos KG, Djoko A, Dompier TP, Kerr ZY. The Epidemiology of deltoid ligament sprains in 25 National Collegiate Athletic Association sports, 2009-2010 through 20142015 academic years. J Athl Train 2017;52(04):350-359

116 Howard DR, Rubin DA, Hillen TJ, et al. Magnetic resonance imaging as a predictor of return to play following syndesmosis (high) ankle sprains in professional football players. Sports Health 2012;4(06):535-543

117 Porter DA, Jaggers RR, Barnes AF, Rund AM. Optimal management of ankle syndesmosis injuries. Open Access J Sports Med 2014;5:173-182

118 Brown TD, Varney TE, Micheli LJ. Malleolar bursitis in figure skaters. Indications for operative and nonoperative treatment. Am J Sports Med 2000;28(01):109-111

119 Matic GT, Sommerfeldt MF, Best TM, Collins CL, Comstock RD, Flanigan DC. Ice hockey injuries among United States high school athletes from 2008/2009-2012/2013. Phys Sportsmed 2015;43 (02):119-125

120 Okanobo H, Khurana B, Sheehan S, Duran-Mendicuti A, Arianjam A, Ledbetter S. Simplified diagnostic algorithm for Lauge-Hansen classification of ankle injuries. Radiographics 2012;32(02):E71-E84

121 Baker JC, Hoover EG, Hillen TJ, Smith MV, Wright RW, Rubin DA. Subradiographic foot and ankle fractures and bone contusions detected by MRI in elite ice hockey players. Am J Sports Med 2016;44(05):1317-1323 